\title{
Child porn offenders, solicitation offenders and child sexual abusers: what the literature has to say
}

\begin{abstract}
This is a review of the literature on those who sexually abuse and molest minors and those who utilize child porn. In reviewing the literature, background factors, psychological and physiological factors, and simply personal choice appear to suggest that most all sexual offenders, regardless of who they target as victims, are more similar than different. The literature has provided contradictory findings about risk issues. One example being the assertion that child porn users and those who engage in online solicitation with minors are somehow less dangerous than contact or dual offenders, despite findings that most all child porn users and those engaged in online contact with victims do indeed have many undetected contact victims. This article will also review the adult rapist because the findings of what we know about the adult rapist are very similar to what we have learned about those who target children or adolescent victims.
\end{abstract}

Volume 7 Issue 4 - 2019

\author{
Scott A Johnson \\ Forensic Consultation, USA
}

Correspondence: Scott A Johnson, Forensic Consultation, USA Emailscott@forensicconsultation.org

Received: June 24, 2019 | Published: August 15, 2019

\section{Introduction}

Understanding the child sexual offender is important. What we have learned about adult sexual offenders in general appear relevant to the child sexual abuser as well. Terminology, definitions, and research protocol often result in confusing findings and can mislead professionals in the field of sexual offenders and law enforcement. Sex offenders tended to be classified as one typology with a handful of motivations. Today we have more specificity in typologies and an understanding of the importance of offender motivation. Many offenders engage in criminal sexual offenses for similar reasons, but each offender may present with unique motivations or backgrounds. It is for that reason that this article was written. Many of the sexual offender typologies overlap in offender motivations and typologies, most offending for the same and similar reasons regardless of whether they are an online or offline offender, or in most cases, both. The problem with undetected sexual offenses is a major difficulty facing professionals in the treatment, adjudication, supervision, and law enforcement fields. Recent research has been clear many child porn only offenders are in fact contact offenders who have not yet been caught, based on self-report and polygraph. Yet there are professionals in the sex offender treatment field that continue to insist that the child porn only offender is not at high risk for contact offenses, despite research telling a different story.

Recidivism is another difficult topic to study. Most sexual offenders, like any criminal offender, tend to have engaged in criminal activity far more than they have gotten caught. In fact, many will likely have been offending for years before their first arrest or conviction. Using the example of speeders, most people who speed have done so on far more occasions than they are cited for a traffic infraction. The same can be said for drunk drivers. No reason to believe that sex offenders are any different. Sex offenders do not typically get caught the first time they offend, as the research suggests. Rape, sexual assault, child sexual abuse, child molestation is not about sex. Sex is used as a weapon to harm the victim or selfishly for the offender's needs. The underlying needs of the sexual offender can be complex and many.
Anyone can find a sexual partner for consensual sex. In fact, many sex offenders have plenty of consensual sexual partners and even have relationships that involve ongoing sexual activity, are involved in a committed dating relationship or even married. Lastly, most sexual offenses against children are vastly undetected and unreported, thereby producing lower rates of victimization than exist. In addition, those offenders who's only known crime involves the use of child porn are most often undetected contact offenders.

Groth $^{1}$ views rape as a tool to satisfy compensatory and retaliatory needs to lessen psychological distress. From this perspective, rape is only remotely related to the need for sex. Rape involves the pairing of sex with power, anger, control, and/or retaliation. As the rapist attempts to cope with their own distress, defective problem solving occurs. The rapist is not "out-of-control" but may feel that they are. I would apply Groth's statements to include child molestation. It appears that the above descriptions of "rape" also apply to most all sex offenders, including the child sexual abuser and child molester. The motivation for sex offenses has to do with many factors, ranging from biological predispositions, environmental factors, and personal choice. How a sex offender copes with the stressors of life and how they problem solve are important considerations the perpetrator considers when choosing to engage in a sex crime. The motivation to commit any sex crime is a choice that the perpetrator makes to feed and meet underlying wants and desires. Needs do not apply here because no one needs to rape for any reason. However, perpetrators have paired intimacy with force, anger with sex, a justification of sex with children or minors, and a distrust of others with a decision that at times forcing sexual contact is safer or more enjoyable and rewarding than consensual sex. Motivation is determined by behavioral patterns and evidence. A careful examination and understanding of the evidence from the crime scene and victim provide clues about the perpetrator's motives.

\section{Definitions}

It is important to understand the difference between child molester, pedophile, hebephilic, and ephebophilia. A pedophile has 
a primary sexual attraction to prepubescent children (typically 12 and under). A hebephilic (hebephilia) has a primary sexual attraction to early adolescents (approximately ages 11-14). A ephebophilic (ephebophilia) has a primary sexual attraction to late aged adolescents (approximately ages 15-19). For most purposes, the term hebephila will be used to include ephebophilia. Any of these three types of sexual abusers may engage in sexual contact with adults for primarily nonsexual needs, such as gaining access to children or for impression management (to appear "normal") or because they are situational offenders who have little or no sexual interest in children. A child molester engages in sexual contact with children for nonsexual needs, and likely has no sexual attraction to children. They are primarily sexually attracted to adults and prefer to engage in sex with adults but will substitute a child sex partner when circumstances or needs arise. A pedophile may limit their behavior to fantasy, objects, clothing, and demonstrate immaturity, but does not always engage in contact sexual offenses with children. Therefore, to be a pedophile does not have to include actual sexual contact with a child. A child sexual abuser and child molester have both engaged in sexual contact with a child and may also have any of the above diagnosis.

Child Porn offender: defines the person who engages in the use of online and offline child porn. In the purest sense, this person has not engaged in solicitation with children online and does not have any known contact sexual offenses involving a child. Child porn and child erotica may include both clothed and unclothed minors and may involve minors posing or engaging in sexual activity alone or with others.

Solicitation offender: defines the person who engages engaged in the solicitation of children or adolescents online to engage in sexual activity. This may involve coercing or seducing the minor to use their webcam for any purpose, including exposing their body, role-playing, or masturbatory activity, or any other active involvement of the victim online. They may/may not engage in the use of child porn online. They may or may not set-up a physical meeting with the victim and therefore engage in a contact offense. Regardless of whether the offender engages in online-only contact or in-person contact, both have now become dual or contact offenders. However, the literature labels the solicitation offender who has acted on contact-driven motivations (engaged in person contact with the victim) and the dual offender one in the same. Solicitation offenders that have attempted to or have engaged in offline physical contact with their victims are dual offenders.

Dual Offender: defines the person who engages in the use of online child porn and has engaged in contact sexual offense behavior (sexual contact) with a child or adolescent (minor). This person likely engages in the solicitation of minors online but may also find victims in the community offline. This also includes solicitation offenders who attempt to have engaged in offline contact with their victim/s.

Child sexual abuser \& contact offender: will be used interchangeably and defines the person who engages in sexual contact with a child or adolescent but does not engage in the use of online child porn. However, this person may use other pornographic material or erotica (anything the person finds sexually arousing) that involves or relates to their preference and selection of victims. The theme of their porn and erotica likely relate to their offense/contact behavior. Many of these offenders may use online and offline child porn but may not have been detected, which would then make them dual or contact offenders.

Contact-Driven Offenders: defines the offender whose primary motivation is to meet with victims and engage in sexual contact. These offenders may solicite minors online with the goal of meeting the victim in person. They generally spend less than one week in online contact before meeting child. ${ }^{2,3}$

Fantasy-driven offenders: these offenders limit their offending to online activities. This may involve those who use child porn and those who seek to interact with victims online. These individuals solicit victims online for sexual activities. Typically, these offenders communicate online with victims on average of days up to around 180 days. $^{2}$ The offender's pornography collection is a good indicator of what they want to do. ${ }^{4}$ Though it does not mean that they have or ever will engage in that theme of behavior depicted or involved in the porn. Research suggests that most fantasy-driven offenders are or will become contact offenders.

Porn: defines any pornographic material. Pornographic material involves sexual themes and ranges from clothed individuals depicted in erotic or directly sexual situations, poses, or activities. It can range from soft-core involving individuals posing, hard-core, involving individuals engaging in sex acts, to extreme or deviant themes depicting and including rape, sadistic sexual acts, and child molestation. The purpose of porn is to provide sexually stimulating material.

Erotica: defines any material or item that serves a sexual purpose for a given person (e.g., objects, magazines, pornographic material (e.g., dvd's, pictures), fetish items, writings, drawings, sexual paraphernalia, vibrators, sex toys, handcuffs, dolls, roll playing). Erotica is not deviant if it involves an age appropriate and consenting partner. Erotica can add to the intimate experience of a person or couple. However, erotica becomes deviant when it involves nonage appropriate people, nonconsenting people, animals, or objects. Erotica becomes deviant and harmful when it behaviorally relates to a crime or other paraphilias (e.g., deviant sexual fantasies, preferences, behaviors. $^{5-7}$

\section{Emotional congruence with children}

Pedophiles and child sexual abusers tend to have an inclination for cognitive and emotional affiliations with children. ${ }^{8}$ This involves identifying with children, psychological immaturity, and substantial time spent with children, all of which limits opportunity to engage in contact with age appropriate peers, limiting relationships with adults. This offender may engage in and maintain relationships with adults who present with their own psychological difficulties or who are significantly younger than the offender, therefore the adult is more vulnerable to the influence and control of the offender. Children may be used interchangeably with adolescent and refers to those under age 18. Much of the research uses the term children when also referencing adolescent victims. Both terms refer to the victim. Rape involves any forced penetrative sexual behavior. The literature on rapists, which primarily focusses on adults who rape other adults, is relevant here because the findings appear to apply to those who target minor victims as well. Rapist backgrounds, issues, attachment difficulties, etc., tend to be similar to those who target children. In this paper the term rape may be used interchangeably with sexual offender, child molesters, to refer to any sex offender.

\section{Factors related to the decision to engage in sexual contact with children or adolescents}

There are differences in opinion on exactly the decision-making process a sex offender goes through to justify acting-out. The theory 
by Neutze and colleagues will be discussed and applies to those who engage in sexual contact with children, use child porn, or produce the child porn (photographers). ${ }^{9}$ The decision to act-out sexually with a child is impacted by the following:

i. Sexual preference (e.g., Pedophilia, any Paraphilia) However, not all child sex offenders are sexually attracted to children and may sexually abuse a child or adolescent for nonsexual needs. ${ }^{4}$

ii. Problems with self-regulation- sexual preoccupation involves difficulty resisting urges, acting on impulse, and acting without regard for the wellbeing of others. Sexual preoccupation is the focusing on sexual activity, porn, any sex related matter and that the focus is primary most every day.

iii. Offense-supportive cognitions refers to thoughts and beliefs that in any way support or condone any offense behavior (e.g., victim blaming, just world theory, abuse/rape supportive thinking, prerogative to take sex or use people sexually). A Socio-affective deficit refers to emotional and attachment areas of the offender's life (e.g., negative emotions, social inadequacy, grievance thinking/hostility towards women, lack of emotional intimacy, intimacy deficits, loneliness).

iv. Offender's ability to cope with everyday problems and sexual urges depends on personal resources and circumstances (e.g., social functioning, SES, employment).

v. Deficits in empathy (e.g., callous-unemotional factors, emotional congruence with child)

vi. Use emotion-oriented problem solving/coping style which involves rationalizing deviant behavior versus addressing the actual problem (e.g., wishful thinking, blaming, covering over with rationalization or justification).

vii. Pedophilia is an important motivation for sexual contact with children; antisocial dispositions are necessary for acting on deviant sexual interests..$^{10,11}$

However, not all who engage in sexual contact with a child online or in person are Pedophiles, some are situational offenders and offend for nonsexual reasons. ${ }^{4,12}$

\section{Catagorizing sex offenders}

I want to begin with a law enforcement motivational typology of sex offenders. Lanning points-out that sex offender should be examined or investigated on a continuum between situational and preferential offenders rather than simply as a specific typology (2009; 2010). This is because many of the specific motivational factors that the offender uses to justify their deviant fantasies and behaviors may change to adapt to a current or dynamic affective state, situational factors, and victim availability. Therefore the sexual offender may act-out with different motivations at different times, selecting a victim that does not usually fit into their sexual preference or desire. They may also on occasion engage in different sexual or violent behavior to meet immediate needs. In addition, I have long argued that two factors that cannot be adequately accounted for in understanding a specific sexual offense include situational or circumstantial factors (these may be different each day, e.g., mood, interaction with others, trauma, cognitive distortions, availability of a victim, being slighted by someone, victim resistance or cooperation). Perhaps the most important factor is the offender's personal choice which is the decision made at the time, which may include doing something that they have or have not ever done before, or have only done on occasion but not their usual behavior. Therefore, understanding the offender's motivation for a specific sex crime is imperative in understanding the offender, which directly relates to how investigators look at a crime and the interview strategies used. For a thorough review of the law enforcement typologies and motivational factors, see Lanning. ${ }^{4}$

\section{Motivation is determined by behavior patterns and evidence}

The motivational continuum is the work of Lanning,, 4,13 Understanding the differentiation of the situational and preferential offender is important. The typologies of sexual offenders need to be understood in relation to the motivation. It is also important to understand that the typologies offer more similarities than differences when describing the background and factors that the offender experienced or used to justify their offense behavior. Lanning, ${ }^{4,13}$ describes four areas to consider when understanding sexual offenses. The underlying needs met for the offender includes various motivational drives. These apply to all sex offenders. The use of Lanning's motivational continuum is useful here.

Many of the examples and factors identified in the literature have focused on the adult sex offender. However, the literature supports that any of the following factors and motivations apply to offenders who sexually abuse minors or engage in the use of child porn. Some examples for each of the four areas may include (but not limited to) the following:

\section{Biological/Physiological Sexual Needs}

Psychosexual/Deviant

$$
\text { Power/Anger Nonsexual Needs }
$$

\section{Biological \& physiological sexual needs}

There is no support for biology for sexual offending or for any of the Paraphilias, including Pedophilia. There is support that biology and genetics may impact offenders in that they may be predisposed to a variety of conditions that challenge everyday functioning and/ or impact coping skills and attachment capabilities. However, no diagnosis or disorder causes Pedophilia, any Paraphilia, or sexually or physically violent behavior. The environment and the offender's personal choice and lack of resiliency explain violent behavior. From a learning theory perspective, the sexually abused-sexual abuser association is explained by learning and imitating sexually deviant or other abusive behavior which is then conditioned by the pairing of any sexual stimulation, and reinforcement occurs as the sexual abuse occurs more than once and then the victim turns perpetrator and reenacts the same sexually abusive acts that happened to themselves on their victims. ${ }^{14,15}$ From a sexual development perspective, sexual abuse may impact psychosexual development and increase sexual offending. Because of sexual abuse, early onset of masturbation may occur as well as the early onset of puberty. ${ }^{15-17}$ 
Familial and other third variables may also impact the sexual abusesexual abuser theory. Family sexual abuse patterns and generations of family members perpetrating sexual abuse may cause the problem to develop and be maintained and reinforced. Genetics may apply here as family members are likely to share genetic contributions to various disorders that may impact boundaries, decision making, antisocial and psychopathic traits, and affective and attachment capabilities. ${ }^{19-20}$ Again, to date there is no evidence of any genetic predisposition for sexual offending specific behavior nor for Pedophilia or any Paraphilia. ${ }^{20,21}$ However, the shared environment may impact these areas as well, thereby making it impossible to separate possible genetic contribution from environmental contribution. Children predisposed to psychopathology are more vulnerable to sexual abuse and therefore more likely to commit sexual abuse if victimized themselves. Adolescents sex offenders have very high rates of having been sexually abused compared to adolescent nonviolent offenders. ${ }^{20}$

\section{Erectile dysfunction}

Approximately 34 to $40 \%$ of rapists' experience difficulty obtaining or maintaining an erection either before or during their rape..$^{22,23}$ One study found that sex offenders, especially those at the highest risk (Level 3) often seek treatment for erectile dysfunction. ${ }^{24}$ It is not known how treatment of erectile dysfunction may impact recidivism. Erectile dysfunction can produce stress and frustration for the offender.

\section{Premature ejaculation}

This involves ejaculation occurring immediately before or immediately following penetration. Approximately $3-12 \%$ of rapists experienced premature ejaculation. ${ }^{22,25}$ This can produce stress and frustration for the offender. In general, men who have self-reported sexual aggression against women, but not convicted of any sex crime, reported significantly more erectile difficulties, orgasmic difficulties, performance anxiety, more sexual embarrassment, and cognitions of undesirability and sexual incompetence than men who have not reported sexual aggression towards women. ${ }^{26}$ Traits of neuroticism (e.g., negative emotionality, social anxiety, low selfesteem, hypersensitivity, nervousness and restlessness) have been associated with sexual dysfunction, especially erectile dysfunction, sexual inadequacies, and premature ejaculation. ${ }^{27}$

\section{Medical conditions}

Chronic medical conditions can interfere with sexual functioning and sexual well-being. Sexual functioning including experiencing "normal" sexual desire and sexual arousal may be impeded as a result of treated and untreated medical conditions. ${ }^{28,29}$ Sexual well-being refers to the cognitive (subjective) experiences and expectations about sexual experiences. ${ }^{30,31}$ Anyone may experience disturbances in sexual functioning or sexual well-being as a result of an accident, stroke, genetics, experience, drug/alcohol use, prescription medication, medical conditions, stress, and self-esteem/cognitions. Individuals may experience problems in both sexual functioning and sexual well-being as they are interrelated. Problem areas may also include neurological disease, vascular disease, and hormonal diseases. ${ }^{32}$

The medical disorders may impact the perpetrator's physical, psychological, and sexual functioning even if the disorders are treated (e.g., the medication may impair sexual functioning) and if untreated may impair psychological and sexual functioning because the perpetrator is not receiving treatment and may experience complications including but not limited to increased irritability, lower self-esteem, impaired sleep, increased or decreased energy, relationship stress, etc., which may produce a situation in which the perpetrator is more stressed and irritable and may demonstrate ineffective coping strategies to address their problem. Basically, medical conditions can impact the perpetrator's life, create more stress and may create dysfunctional body image or self-performance issues- though these do not cause a person to rape or sexually abuse minors, these conditions may increase stress and negative emotions and a distorted self-image and self- worth.

\section{Increased testosterone levels (Hormonal Disorder)}

High Testosterone levels appear related to sexual aggression. ${ }^{33}$ Testosterone has also been correlated with Antisocial Personality Disorder. ${ }^{34}$ High Testosterone levels are related to general sensation seeking tendencies ${ }^{35}$ and more reported histories of antisocial conduct and relationship difficulties. ${ }^{34}$ Now to what degree high Testosterone contributes to aggression and sex offenses independent of Antisocial Personality Disorder (APD) is difficult to determine. Having APD may in and of itself provide a predisposition for violent behavior. High Testosterone levels may increase sexual desire and appetite but may not in and of itself play a major role in choosing rape or child sexually abusing behavior without APD factors. Kleinfelter's Disorder is a chromosomal abnormality found in a few pedophiles. ${ }^{36}$ Berlin et al., ${ }^{37}$ conceded that Kleinfelter's did not account for specific sexual interest in children.

\section{Mental disorders}

The diagnosis of any mental disorder infers that the individual experiences a constellation of symptoms that have been found to be deviant (deviant because most people in society do not experience these symptoms to a significant degree or the combination of symptoms for a specific amount of time) from the general population and therefore to warrant a diagnosis. The Diagnostic and Statistical Manual of Mental Disorders, ${ }^{11}$ describes the mental disorders and their symptoms. Mental disorders often have some biological or genetic factor but more importantly the environment helps to shape these disorders (e.g., home life, abuse and neglect, criminal family environment, family members with disorders modelling the deviant behavior and thinking, and permissive parenting (e.g., treating children as if they were adults with little or no discipline or consequences for inappropriate behavior, or on the other extreme permissive neglectful- not responding to the child's need, not affirming the child's existence or worth).

In addition, the individual may help create and foster the mental disorder by their choice of behavior and thinking patterns. Regardless, mental disorders do not cause anyone to behave in assaultive behavior or in sexually assaultive/rape behavior, but rather set the background for how the perpetrator justifies their actions. Neuroticism in general appears to be higher for sex offenders and child molesters..$^{27,38,39}$ Neuroticism can impact both psychological and physiological functioning (e.g., erectile dysfunction, retarded or premature ejaculation, performance anxiety). Social anxiety has been moderately associated with sex offenders. ${ }^{40}$ The most prevalent Axis 1 diagnosis for adolescent and adult sex offenders include mood disorders $(72 \%)$, anxiety disorders (approximately 39\%), social phobia (approximately $22 \%$ ), and substance abuse (alcohol and cocaine). ${ }^{41}$ ADHD was found to be the third most common Axis 1 disorder. ADHD was also found to be associated with the propensity for multiple Paraphilias and higher likelihood of incarceration. ${ }^{41}$ Approximately 44\% of Paraphilics presented with ADHD. Kafka et al., ${ }^{42}$ found that ADHD and Cocaine abuse were significantly more prevalent in Paraphilic males. Mood 
disorders and impulsivity disorders (including ADHD, Conduct Disorder) have been found in male sex offenders, which increases risk for reoffense. ${ }^{41,43,44}$

\section{Substance use disorder}

Approximately $23 \%-85 \%$ of sexual offenders were reported to have a substance use disorder. ${ }^{43,45-50}$ Approximately $25 \%$ having a history of alcohol abuse and $20 \%$ a history of drug misuse. ${ }^{48}$ Sex offenders tended to demonstrate the same percentage of substance abuse problems regardless of the type of sex offender (e.g., female or male perpetrator, rapist of adults, child molester, etc. $)^{49,51-54}$ However, substance use and abuse never cause anyone to engage in rape, child molestation, or any other violent crime..$^{55}$ Based on selfreport, studies show that between $2-86 \%$ of sex offenders claim they were intoxicated at the time of their crime though this was largely based on self-report. ${ }^{50,56,57}$ Overall, the research has been inconsistent when differentiating substance use/abuse between rapists and child molesters and therefore it is difficult to discern any significant difference between the substance use/abuse of the two groups. ${ }^{48,51-58}$ Again, much of the substance use and substance abuse data was gathered from offender self-report. It is not common that an offender was arrested and tested for drug and alcohol use until sometime after the offense.

\section{Attention-deficit/hyperactivity disorder (ADHD)}

This disorder involves the persistent pattern of inattention and/or hyperactivity-impulsivity. These behaviors impact the individual's life, making it difficult to focus and interact with others in socially appropriate ways. Research has demonstrated that rapists with a childhood history of ADHD reported engaging in aggression and had a life-time history of aggression and impulsivity. Giotakos et al., ${ }^{59}$ found that a history of childhood ADHD symptoms in their sample of rapists was linked to "...higher levels of aggression, impulsivity, and suicidality, a temperament profile characterized by frequent exploratory activity and quick loss of temper, and a character profile characterized by purposeless, difficulty accepting others, and lack of empathy" (pp. 423). Personality factors involved in ADHD may place those with the diagnosis at risk for choosing to engage in violent behavior. Kafka et al., ${ }^{42}$ found that "....childhood ADHD was the only Axis I disorder statistically significantly associated with paraphilias and socially deviant and aggressive forms of sexual impulsivity. Those findings were replicated by Kafka et al. ${ }^{41}$

However, nowhere does the literature demonstrate that having ADHD causes rape nor is there any evidence that most people with ADHD engage in sex crimes. The very nature of ADHD may lead to the individual choosing to engage in violent behavior, but not all do. In addition, the personality factors associated with ADHD are also present with Antisocial Personality Disorder as these two diagnoses often occur together in adulthood. Having ADHD is never an excuse for rape but is sometimes used as a defense by rapists. This does not cause a person to behave violently or to engage in rape but may be a reason used by a perpetrator for their choice to rape. Consider the complexities involved in rape, which require a perpetrator to focus on the victim, the situation and location, as well as on the desired sexual and violent conduct. Individuals with ADHD would more likely engage in a disorganized rape and more likely to make mistakes impacted by the inattention. For those with ADHD that commit an organized rape, they had to focus harder and therefore were not likely impacted much at all by the ADHD symptoms. Regardless, ADHD does not cause rape to occur.

\section{Mood \& anxiety disorders}

Mood disorders are characterized by a depressed mood and a loss of pleasure in activities. These symptoms can impact physical and psychological health. Approximately $40 \%$ of sexual offenders present with a mood disorder. ${ }^{43}$ Those with paraphilias had co-occurring mood and anxiety disorders. ${ }^{43}$ Manic depression is characterized by persistently elevated, expansive and irritable mood. This involves an inflated self-esteem or grandiosity, decreased need for sleep, distractibility and psychomotor agitation. Negative mood states have been found to precipitate or immediately precede a sex offense. ${ }^{60-65}$ Anxiety disorders are characterized by extreme anxiety and worry, may involve fear, need for perfectionism, or post-traumatic stress disorder which involves the re-experiencing of an extremely traumatic event and includes physiological and psychological arousal. Anxiety disorders (specifically social anxiety) are common among sex offenders and child molesters ${ }^{66-68}$ Both mood and anxiety disorders may impact the perpetrator's life in several negative ways, including but not limited to low self-esteem, low energy, a lack of confidence, fear of not being good enough or fear of specific situations, and increasing social isolation. Mood disorders and anxiety are often comorbid that is, occurring together at some point for the individual. Violent offenders in general tend to be more extroverted than rapists or child molesters. This introversion may impede appropriate social interaction and relationship skills. ${ }^{69}$ Violent offenders generally attack strangers, rapists generally attack acquaintances, and child molesters typically attack relatives and friends. ${ }^{69}$ This may speak to the offender's limited relationship and attachment skills. Treatment for anxiety and depressive disorders and symptoms may help reduce impulsivity and sexual impulsivity. ${ }^{70}$ The treatment of Axis 1 disorders does not eliminate sexual or violent offenses but rather helps to decrease impulsive urges, thereby allowing the offender to feel less pressure to act-out, though still the onus is on the offender to choose to not engages in sexual and nonsexual offense behavior.

\section{Social anxiety}

Social Anxiety Disorder involves experiencing intense fear and anxiety about social situations in which the person may face scrutiny by others, be rejected or negatively evaluated by others, and therefore the person avoids social situations. ${ }^{11}$ Social, interpersonal, and intimacy deficits are common characteristics of sex offenders. ${ }^{68}$ Social anxiety often results in social isolation and limited intimate relationships. Contact child sexual abusers had higher rates of social anxiety when they had the diagnosis of Pedophilia, ${ }^{58}$ or any Paraphilia, ${ }^{71}$ or had exclusively male victims. ${ }^{71}$ Some of the research on social anxiety as it relates to sexual offenders is flawed in part due to the lack of consistent research protocol, definitions used (many of the studies predate the 2000's) as well as problematic assessment protocols used (some programs and researchers may not have assessed for and therefore failed to diagnose anxiety or other related disorders).$^{40}$

In addition, determining whether the sex offender or child molester experienced social anxiety or other Axis 1 disorders prior to offending versus following arrest, conviction and incarceration for sexual offending is nearly impossible..$^{67,72}$ Being arrested and convicted of a sex crime may be traumatizing for the offender and they may develop Axis 1 disorders, including social anxiety. ${ }^{73}$ Despite the above 
concerns, it appears that the relationship between social anxiety and paraphilic disorders is moderate to strong. Some research suggests that child molesters experience greater anxiety than sex offenders with adult victims but only slightly more anxious than non-sex offenders. ${ }^{67}$

\section{Childhood victimization}

It is estimated that approximately $19 \%$ to nearly $60 \%$ of sex offenders were the victim of physical and/or sexual abuse. ${ }^{74}$ It should be clear that the majority of victims of childhood physical and/or sexual abuse do not engage in sexual or nonsexual offenses (approximately $12 \%$ to $21 \%$ did go on to sexually offend). ${ }^{75,76}$ Approximately $12 \%$ to $90 \%$ of adolescent sex offenders reported having been sexually abused. ${ }^{20}$ Those who did, were victims of sexual abuse and witnessed parental violence, being physically abused, and discontinuity of care. ${ }^{75}$ Domestic violence and therefore witnessing domestic violence were common in the families of adolescent sexual offenders and adolescent violent nonsexual offenders. ${ }^{77-81}$ Within families characterized by a high prevalence of abuse, sexual abuse was high. ${ }^{79}$ Approximately $20 \%$ of abusive families were found to be high prevalence families where physical and sexual abuse occurred, $50 \%$ of families were found to be low prevalence families in which one form of abuse occurred. ${ }^{79}$ One study found that $80 \%$ of adolescent sexual offenders were victims of both childhood physical and sexual abuse and only approximately $22 \%$ were victims of only physical abuse. ${ }^{79}$ Although witnessing parental violence and/or being the victim of childhood physical abuse are important factors, childhood sexual abuse is one of the strongest developmental factors associated with adolescent sexual offending. ${ }^{82-84}$

It is possible that abuse becomes normalized in families with multiple family members engaging in abusive behavior and that the parents fail to provide necessary support for the victims (e.g., parenting styles that were neglectful, rejecting, or anxiety-provoking) which in turn may lead to negative outcomes such as externalizing behaviors including sexually abusive behavior. ${ }^{14,85,86}$ The impact of childhood abuse is likely to result in the development of less effective coping skills and an increased vulnerability for developing mental health disorders ${ }^{87}$ as well as on childhood and adolescent development. ${ }^{82,84,88,89}$ Child sexual abuse can significantly impact the development of attachment bonds thereby impacting future relationships. ${ }^{84,90}$ Specifically, social anxiety is a common disorder resulting from childhood trauma and abuse. Social anxiety is likely to influence the development of sexual preference and paraphilic disorders, ${ }^{21}$ as well as increase the development of social skills deficits, social avoidance, or fear of negative evaluation (impression management problems), which are all implicated in the development and maintenance of sexual offending. ${ }^{91}$ In addition, social anxiety impacts interpersonal relationships and maintains social fears thereby increasing the likelihood for depressive disorders and substance abuse (though one caveat is important- it is nearly impossible to determine which of the mental health disorders predate any other mental health disorder, thereby only correlating that one is likely to lead to or be impacted by the others). ${ }^{92,93}$ Adolescence is a critical time period for sexual development and the establishment of social relationships.

Individuals who experienced emotional, physical, and/or sexual abuse as children are at increased risk for developing anxiety disorders, social anxiety being on the most common for those who become sex offenders (as well as for those in the general population). ${ }^{40,43,87}$
Sex offenders, especially adolescent male sex offenders, were far more likely to have been sexually abused than non-sex offenders. ${ }^{20}$ Rapists (having adult victims) tended to be the victim of childhood physical abuse whereas child molesters tended to be the victim of sexual abuse. ${ }^{76,94}$ The association of having been sexually abused in childhood is strong among adult sex offenders but less significant than histories of physical or emotional abuse or neglect. ${ }^{20,21}$ Childhood sexual abuse, like any other form of maltreatment, does not occur in isolation. Environments in which sexual abuse occur typically have other forms of abuse occurring as well, with violence being directed at numerous family members, substance use/abuse issues, and criminal behavior in general. ${ }^{21,75,94}$ Though it is difficult to separate which problems occurred in what order, they often occur together as any one problem occurs. Having been sexually abused is correlated with all types of sex crimes; physical abuse more related to crimes of rape and sodomy and sexual abuse related to committing sexual crimes against children. ${ }^{21,76,94}$

Sex offenders against children have significantly higher rates of reporting childhood sexual abuse and subsequent Pedophilic interests, ${ }^{21,95-97}$ as well as early exposure to porn, early onset of masturbation, and sex with animals. ${ }^{97}$ Most adolescent sexual offenders against children had histories of sexual and physical abuse. Physical abuse may result in the development of callous-unemotional traits associated with antisocial behavior and aggression. ${ }^{98}$ offenders against adults reported more childhood physical abuse, parental violence, emotional abuse, and cruelty to animals. ${ }^{97}$ Salter ${ }^{99}$ found that rapists tended to have more problems with anger and assertiveness and were more likely to become intoxicated before or during the sex offense. She also indicated that they were more likely to have a personality disorder as well as be more opportunistic. ${ }^{100}$ Child molesters often suffer from depression and anxiety related disorders, are more premeditated in their offense planning, and report experiencing more deviant sexual fantasies than rapists. ${ }^{99}$ They also tend to use less alcohol during the commission of their sex offenses. Salter et al., ${ }^{75}$ also found that sexually abused boys who sexually offended were often victimized by a female perpetrator.

\section{Antisocial personality disorder}

Antisocial Personality Disorder (APD) involves the pervasive disregard for the rights of others and may include a lack of remorse, impulsivity, assault, lying, failing to follow social norms, and irresponsibility. ${ }^{11}$ People with APD do what they want when they want regardless of the consequences to self or others. Often referred to as criminals or thugs, individuals with APD tend to hurt others and break the law without regard for the impact on others. People with APD typically had problems as children and adolescents with oppositional and aggressive behavior as well. Many may have experienced violence or other asocial behavior in the home and may have also had parents with APD or other antisocial tendencies. Rapists and violent offenders will likely have APD and share much in common. ${ }^{101,102}$ Sex offenders in general tend to have APD, in fact most do. ${ }^{47,103-105}$ Groth linked rape to power, anger, and sexuality, which links it to violence. ${ }^{1,101}$ Psychopathy and aggression generalize to all forms of violence, including sexual violence. ${ }^{106-108}$ People with APD tend to experience difficulties in their relationships and in society and are likely to have frequent interaction with the legal system and law enforcement. Their relationships tend to be strained and family and 
friends tend to support the deviant thinking and behavior. For a more thorough review of Antisocial Personality Disorder, Sociopathy, and Psychopathy, see Johnson. ${ }^{12}$

\section{Psychopathy}

Psychopaths can be described as engaging in the callous and remorseless use of others and demonstrate chronically unstable and antisocial lifestyles. ${ }^{109,110}$ Psychopaths demonstrate a callous disregard for the rights of others, a propensity for predatory and violent behavior, a lack empathy, a lack of remorse, a lack of any sense of responsibility, pathological lying (lying for the sake of lying), callousness, shallow affect, use and exploit others for their own gain. Psychopaths engage in high impulsivity, risk taking and fearlessness. ${ }^{110}$ They engage in predatory and stalking behavior and lack conscience. ${ }^{109}$ They have attachment deficits that are evident in childhood. ${ }^{111-113}$ In childhood, psychopaths often demonstrate significant impulsivity, insensitivity, and problem externalization, ${ }^{114,115}$ as well as a social and antisocial behavior at an early age. ${ }^{116}$ Psychopathy involves significant frontal lobe and amygdala impairment as well as impairment in the limbic system. ${ }^{116-118}$ Deficits include lack of fear, impulsivity, impaired behavioral inhibition, sexual promiscuity, lack of remorse, and antisocial tendencies. ${ }^{119}$ The right hemisphere of the brain demonstrates hypoactivity while the left hemisphere demonstrates hyperactivity. This is significant because the right hemisphere involves prosocial tendencies and the left hemisphere involves aggression, impulsivity, sensation-seeking, and risk-taking behaviors. In addition, the corpus callosum is slower in allowing communication between left and right hemispheres. ${ }^{116}$ High levels of testosterone are also found in psychopaths. ${ }^{116}$

\section{Sociopathy}

Sociopaths differ from psychopaths in that they are born with fairly normal neurological development. Environmental factors, such as early adverse events (e.g., abuse, neglect), parenting styles such as permissive indulgent parenting (treating your child as an adult and rarely if ever disciplining or setting limits), permissive neglectful parenting (providing for your child's basic needs but having little if any emotional connection or other involvement with the child, ignoring the child), fatherlessness, and a lack of socialization. ${ }^{120}$ Sociopaths may experience some degree of remorse and guilt within the context of some group (e.g., gang, family). This is a form of gross under socialization. They will demonstrate many if not all of the same traits and behaviors as psychopaths ${ }^{121}$ though they are significantly more impulsive and demonstrate little behavioral control (though not out-of-control). Psychopaths and sociopaths are wired to hurt others. However, not all engage in violent behavior and not all engage in rape or other sex assault behavior. Psychopaths and sociopaths know that what they are doing is wrong, they just do not care. They do not fear the consequences nor are they capable of remorse or conscience (though some sociopaths demonstrate some degree of conscience). For a current review of the impact of violent personality, sociopathy and psychopathy, see Johnson. ${ }^{12}$

\section{Power \& anger \& other nonsexual needs}

Power, anger, control and revenge tend to be associated with all sex offenders' decision to offend, though not all present with each of these four. How the offender justifies using sex to address these factors/emotions is unique to the individual offender.

\section{Poor problem-solving skills}

Sex offenders tend to have poor problem-solving skills. They may be effective at their work at church, and with friends and family. They may be married and appear "normal". However emotional regulation issues, poor attachment skills, ineffective communication skills, and ineffective coping skills may impact an offender's decision to offend, use of excessive force (force beyond that which is necessary to gain victim compliance) does not always provide increased sexual arousal for the rapist. ${ }^{84,122}$ All sexual assaults and rapes appear to be perpetrated in order to meet the rapist's need for power ${ }^{84}$ but not necessarily for the damage or injury of the victim. Groth ${ }^{1}$ proffers that all sexual assaults and rapes involve power, anger, and sexuality, ${ }^{101}$ all of which make sense because rape is an aggressive act. It is through the rape that the rapist experiences a relief from a variety of negative emotional states such as feelings of anger, frustration, resentment, rage, inadequacy, and loneliness. More importantly, rape and sexual assault are never simply about sex.

\section{Psychosexual/deviant}

This category includes the specific paraphilia the offender demonstrates. This includes Pedophilia, Hebephilia (sexual attraction to adolescents approximately ages 12-15) or Haebephilic (sexual attraction to older adolescents), Voyeurism, Exhibitionism, etc., the offender may well demonstrate more than one paraphilia. Many may have Paraphilia, Unspecified, with the adjective that best describes their preference or deviant behavior in parenthesis (e.g., Paraphilia, Unspecified (rape, forced sex, rough sex, etc).

\section{Sexual needs}

This category includes the offender's specific, self-defined sexual needs and expectations. This may include cognitive distortions about sex, derogatory views of women or children, beliefs justifying use of force, coercion, or seduction. A thorough interview with the victim may reveal what the offender said to the victim, what the victim was told to do or say, what specific behavior (sexual and nonsexual) the offender chose to engage in and even as important, what the offender chose not to do (e.g., engaged in vaginal intercourse but not anal intercourse), all of which helps identify the offender's sexual and nonsexual needs. Again, to reiterate, none of the above factors or disorders cause anyone to behave violently or to engage in any sexual offense behavior.

\section{Situational \& preferential sexual offenders \& child molesters}

It is also important to understand the difference between the situational and preferential sex offender. The situational offender prefers sex with an adult, may have little or no sexual attraction towards children, but chooses to sexually abuse or molest a child for nonsexual needs or desires. The preferential child molester has a primary sexual attraction to children or adolescents but may still engage in sexual behavior with adults for a variety of nonsexual needs (e.g., to access victims, to appear "normal", out of curiosity). The following is a comparison chart based on Lanning's work ${ }^{4,13}$ (Table 1).

\section{Specific typologies of child molesters}

In understanding the situational and preferential child molester (which includes any minor victim) we can now turn to specific sex offender typologies for those who target children and adolescent victims. I will begin with a law enforcement typology by Lanning., ${ }^{5,13}$ We will then explore other typologies. 
Table I Situational and preferential sex offenders. ${ }^{4,5,13}$

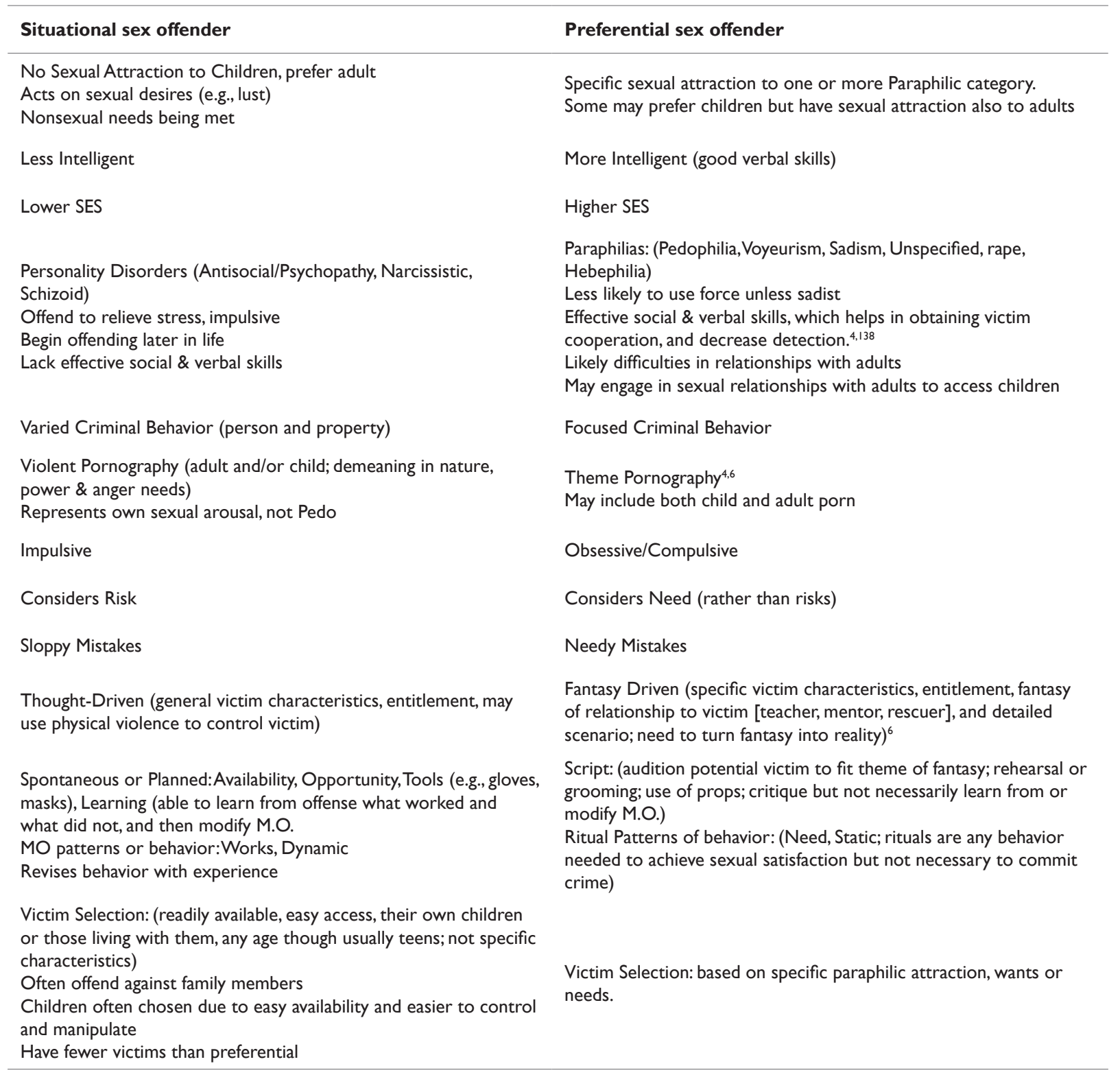

\section{Law enforcement typology situational child molester}

The situational child molester typically has fewer child victims and other victims may include anyone of any age who is vulnerable. Most sexually motivated child murderers are situational- type offenders including the Morally Indiscriminate and the Inadequate. ${ }^{13}$ Low selfconfidence may be primary motive for abducting victims. ${ }^{5}$ (Table 2 ).

\section{Preferential child molester}

Preferential child molesters generally have large numbers of victims. ${ }^{13}$ They have a preference for children sexually and a need for frequent sexual behavior (Table 3).

\section{Internet child sexual offenders}

The terminology used to describe online child sexual offenders has been inconsistent and often confusing. Terms like child porn

offender have been used to include those viewing or collecting adolescent porn, so in fact child porn includes porn involving any minor. The Internet child sexual offenders appear diverse in their behavior and motivation for engaging in deviant and criminal sexual behavior. In summary, there does not appear to be a set demographic profile for Internet offenders. The research presents mixed findings and online only offenders often share many characteristics with dual offenders (Internet and contact) as well as with contact only offenders/ child sexual abusers as well as with child porn only or solicitation offenders. In addition, it is difficult to trust that those identified as being child porn offenders have not engaged in solicitation behavior or direct contact behavior given the crossover data and the fact that over half will admit to having undetected contact offenses. Therefore, the differences are not as significant as once expected. The following information is what the current literature has to offer. 
Table 2 Law enforcement typology situational child molester. ${ }^{4,5,13}$

\begin{tabular}{|c|c|c|c|}
\hline & Regressed & Morally indiscriminate & Inadequate \\
\hline $\begin{array}{l}\text { Basic } \\
\text { Characteristics }\end{array}$ & $\begin{array}{l}\text { Low self-esteem } \\
\text { Poor coping skills } \\
\text { stressed }\end{array}$ & $\begin{array}{l}\text { User of people } \\
\text { Antisocial PD or psychopath }\end{array}$ & $\begin{array}{ll}- & \text { Social misfit } \\
- & \text { Maybe psychotic } \\
- & \text { Eccentric PD } \\
- & \text { Mental retardation } \\
- & \text { Withdrawn } \\
- & \text { Unusual } \\
- & \text { No friends or younger } \\
\text { friends } & \\
- & \text { Adult who still resides with } \\
\text { parents } & \\
- & \text { Lacks grooming/ seduction } \\
\text { skills } & \end{array}$ \\
\hline Motivation & Substitution & Why Not? opportunity & $\begin{array}{ll}- & \text { Insecurity \& Curiosity } \\
- & \text { Anger \& resentment }\end{array}$ \\
\hline Victim criteria & $\begin{array}{l}\text { Availability (may molest own } \\
\text { children) }\end{array}$ & $\begin{array}{l}\text { Vulnerability \& opportunity } \\
\text { abuses anyone- strangers, acquaintances } \\
\text { live-in partner's child }\end{array}$ & $\begin{array}{ll}- & \text { Non-Threatening } \\
- & \text { Stranger or acquaintance } \\
- & \text { May be substitute for known } \\
\text { adult } & \\
- & \text { Any age, including elderly }\end{array}$ \\
\hline $\begin{array}{l}\text { Method of } \\
\text { operation }\end{array}$ & Coercion & Lure, force, or manipulate, may abduct & $\begin{array}{l}\text { Exploits size, advantage } \\
\text { May vent frustration in cruel } \\
\text { sexual torture }\end{array}$ \\
\hline $\begin{array}{l}\text { Pornography } \\
\text { collection }\end{array}$ & $\begin{array}{l}\text { Possible child or adult } \\
\text { If has child porn- likely } \\
\text { homemade }\end{array}$ & $\begin{array}{l}\text { Sadomasochistic, detective magazines, } \\
\text { violent porn } \\
\text { adult \& maybe child porn }\end{array}$ & Likely adult \\
\hline
\end{tabular}

Table 3 Preferential child molester. ${ }^{4,5,13}$

\begin{tabular}{|c|c|c|c|c|}
\hline & Seduction & Introverted & Sadistic & $\begin{array}{l}\text { Diverse: sexually } \\
\text { indiscriminate }\end{array}$ \\
\hline Aracteristics & $\begin{array}{l}\text { Sexual Preference for Children } \\
\text { Collects Child Pornography or } \\
\text { Erotica } \\
\text { Good communication and listening } \\
\text { skills } \\
\text { Most acquaintance CM's }\end{array}$ & $\begin{array}{l}\text { Lacks interpersonal skills } \\
\text { Minimal amount of commu- } \\
\text { nication with victims } \\
\text { Likely to hang around } \\
\text { playgrounds, engaging with } \\
\text { children } \\
\text { Exhibitionism, obscene } \\
\text { phone calls } \\
\text { May use services, internatio- } \\
\text { nal contacts } \\
\text { May marry to have children } \\
\text { and immediately begin mo- } \\
\text { lesting them after birth } \\
\text { Similarly to the Inadequate }\end{array}$ & $\begin{array}{l}\text { Cause pain, fear, } \\
\text { humiliation } \\
\text { Aroused to victim's } \\
\text { response to torture/ } \\
\text { pain } \\
\text { Lures or uses physical } \\
\text { force to obtain victim } \\
\text { may abduct strangers } \\
\text { Seductor CM's may } \\
\text { become sadistic } \\
\text { If molests own victim, } \\
\text { likely to kill to prevent } \\
\text { disclosure } \\
\text { Keeps victim for long } \\
\text { periods of time }\end{array}$ & $\begin{array}{l}\text { Sexual Experimentation } \\
\text { Try anything offender } \\
\text { Not necessarily Pedo, but } \\
\text { may molest children } \\
\text { May have specific Paraphilic } \\
\text { interests } \\
\text { Engages any victim or child } \\
\text { in preferred Paraphilic } \\
\text { behavior } \\
\text { May engage in partner } \\
\text { swapping, child swapping, } \\
\text { or bizarre sexual ritual } \\
\text { May utilize Internet to } \\
\text { communicate with women } \\
\text { to offer-up their children }\end{array}$ \\
\hline Motivation & Identification & Fear of Communication & Need to Inflict Pain & Boredom Children are new \\
\hline $\begin{array}{l}\text { Victim } \\
\text { criteria }\end{array}$ & $\begin{array}{l}\text { Age and Gender Preferences Multiple } \\
\text { victims simultaneously (same class, } \\
\text { neighborhood) } \\
\text { Often risky children (e.g., dysfunction } \\
\text { al home, abuse) }\end{array}$ & $\begin{array}{l}\text { Strangers or Very Young } \\
\text { Likely simultaneously } \\
\text { molesting others }\end{array}$ & $\begin{array}{l}\text { Age and Gender } \\
\text { Preferences }\end{array}$ & $\begin{array}{l}\text { New \& Different } \\
\text { May molest his own } \\
\text { children, step-children }\end{array}$ \\
\hline $\begin{array}{l}\text { Method of } \\
\text { operation }\end{array}$ & $\begin{array}{l}\text { Seduction Process } \\
\text { Lowers victim's inhibitions } \\
\text { May use threats and physical violence } \\
\text { to avoid detection or prevent victim } \\
\text { from leaving the relationship }\end{array}$ & Nonverbal Sexual Contact & Lure or Force & Involve in Existing Activity \\
\hline $\begin{array}{l}\text { Porn } \\
\text { collection }\end{array}$ & $\begin{array}{l}\text { Likely child porn, mixed with some } \\
\text { adults } \\
\text { Homemade }\end{array}$ & Specific to preference & $\begin{array}{l}\text { May or may not have } \\
\text { porn collection } \\
\text { Specific to preference }\end{array}$ & Highly Likely;Varied Nature \\
\hline
\end{tabular}




\section{Paraphilias}

Addressing Paraphilias, and specifically Pedophilia, it is important to thoroughly assess and provide all appropriate diagnoses for a specific offender. Many will likely have two or more Paraphilias. Some research found that possession of child porn was a valid indicator of Pedophilia (though the researchers did not specify whether the offender was only sexually attracted to prepubescent children or to children and adults). ${ }^{123,124}$ Another researcher found that only approximately $25 \%$ of their sample of Internet offenders were Pedophilic; $50 \%$ were diagnosed as Paraphilia NOS (not otherwise specified, which likely includes situational child molesters who do not have a primary sexual interest in children or may not have any sexual attraction to children and offend sexually against children for nonsexual needs). ${ }^{125}$ Online offenders might exhibit greater sexual deviance than contact offenders and some differed in psychological factors that may act to protect them from committing contact sexual offenses (e.g., greater victim empathy, less emotional identification with children, fewer cognitive distortions). ${ }^{126,127}$

\section{Relationship between the victim and offender}

Most children are sexually abused by people they and/or their family know and trust. The offender engages in strategies including selecting a vulnerable victim, gaining access to the victim, developing trust, and then desensitizing the victim to touch. ${ }^{128}$ Many of the grooming behaviors appear innocent in nature. ${ }^{129}$ Approximately $60 \%$ of the perpetrators are known to the child but are not family members; $30-45 \%$ are family members; $42 \%$ acquaintances; $3-10 \%$ are strangers to the child; and approximately $23 \%$ of cases the perpetrator is under age 18 , and $90 \%$ of the perpetrators are male. ${ }^{130-137}$ Individuals most likely to sexually abuse a child had opportunity and access. ${ }^{13,113,138}$ Most child porn offenders (approximately $70 \%$ ) have access to children in the community with at least $25 \%$ in a position of power or trust over children. ${ }^{135}$

\section{Child porn offender typologies}

\section{Online child sex offender typology 13}

Lanning identified 4 types of child porn offenders based on motivation:

a. Those who access child pornography impulsively or out of curiosity, but have no specific sexual interest in children;

b. Those who view child porn to satisfy sexual fantasies but do not engage in contact;

c. Those who produce and distribute child porn for financial gain; and

d. Those who use the internet to facilitate contact sex offenses against children.

Krone $^{139}$ provides a thorough outline of the numerous types of motivations that child porn offenders present with. Some offenders engage in the production or collection of child porn for solely nonsexual reasons, treating the child porn as a commodity. Others have motivations involving sexual contact and exploitation of the children. Below is a summary. ${ }^{139,140}$

\section{Direct victimization}

This category includes those offenders who have a sexual attraction to children as well as those who are situational offenders (having no sexual attraction to children) and choose to engage in actual sexual contact with children or adolescents. This encompasses the dual and contact offenders. These offenders are likely to take pictures and make videos of the sexual contact they engage in with children or adolescents.

\section{Commercial exploitation}

This category includes those who trade child porn as a commodity and may or may not have any sexual attraction to children. These offenders simply view the production, trading and dissemination of child porn as a business. About $40 \%$ of these have been found to have actually sexually abused children and were therefore dual offenders who may not yet have been detected. ${ }^{131}$

\section{Periodically prurient offender}

Access child porn impulsively or out of curiosity as part of interest in porn they have lewd and sexual thoughts. This category captures offenders who are Pedophilic, Hebephilic, or Ephebophilic as well as the situational sexual offender. ${ }^{4,5}$ These offenders likely have a sexual attraction to children or adolescents and experience sexually orientated fantasies of minors and likely a desire to act on their thoughts and impulses. These offenders are not out-of-control but may feel as though they are driven to act on their fantasies and desires. These offenders present with the following ${ }^{139,140}$

a. Socio-affective deficits (low self-regulation and inhibitory control)

b. Emotionally inadequate and are the deviant offender group.

c. Some difficulties appropriately controlling behavior though may or may not have many impulsivity problems.

d. May have severe interpersonal problems.

e. These offenders appear to follow the Emotional Dysregulation Pathway ${ }^{141}$ of offending. They experience difficulty successfully regulating negative emotions and use sex as a coping mechanism (related to antisocial traits). They may claim nonsexual motivations toward children but rather use child porn to avoid real life confrontations or to gain pleasure from collecting child porn. They have few cognitive distortions about sex with children and deny emotional congruence with children, but some lack empathy for sex abuse victims.

\section{Fantasy-only offenders}

These offenders restrict their deviant behavior to online use of child porn. However, many may engage in solicitation of children and adolescents online involving sexual behavior. Again, one caveat, is that many will likely crossover to becoming contact offenders. ${ }^{139,140}$

a. Pedophilic interest is main reason why uses child porn.

b. Fixated sexual interest on child porn and usually begins to masturbate immediately when looking at porn.

c. Put own feelings before childs.

d. Adverse early life experiences may lead to intimacy deficits and loneliness. This follows the Intimacy Deficits Pathway. ${ }^{141}$ Due to insecure attachment, they have difficulties with adult intimate relationships.

e. The experience emotional loneliness, low self-esteem, cognitive distortions about children and sex, poor social skills. 
f. They are more attracted to children as sex partners when lonely or when dissatisfied with adult relationships.

g. They experience emotional congruence with children.

h. They demonstrate distorted victim empathy.

i. Some had criminality.

\section{Child porn only offenders}

Internet only, no known contact offenses and no solicitation this is also referred to as Child Exploitation Material Offenders (CEM). The problematic reference to child porn only offender raises concerns because most self-report having contact victims that were not yet detected.

\section{Demographics \& education}

Higher educational background. ${ }^{136,142-147}$ Other data suggests that online and offline child sexual offenders were found to have similar educational levels. ${ }^{126}$

a. Tend to have higher IQ. ${ }^{127}$

b. Tended to be younger and most Caucasian. ${ }^{148-156}$

c. Others found that about $65 \%$ of the child porn offenders were Caucasian. ${ }^{157}$

d. Ages 25-50. ${ }^{158}$

e. Although most child porn offenders are male, some studies have suggested that between 1-33\% may be female offenders. ${ }^{159-161}$

f. They are more likely to reside with children than contact and solicitation offenders. ${ }^{147}$

\section{Employment status}

Most were employed with stable employment. ${ }^{162,163}$

a. Some found to be unemployed. ${ }^{126}$

b. Many employed in professional jobs requiring a degree. ${ }^{164,165}$

c. $23 \%$ retired. ${ }^{158}$

d. Jobs with little/no contact with others or contact with children with/without supervision. ${ }^{158}$

\section{Relationships status}

About half of internet offenders married; half maybe not in a relationship or never married..$^{142-149,166-168}$ The lack of marital history suggests that they may avoid emotional closeness in sexual relationships with adults or they may experience deficits in social skills or intimacy. Some have never lived with a lover; ${ }^{147}$ More likely to be living with their parents and single. ${ }^{169}$ Less contact with people in the offline world; ${ }^{170}$ Tend to have poor relationship stability. ${ }^{147}$ It may be possible that the reason some child porn users do not engage in contact offenses with children is that they may not have access to children. Many child porn offenders are divorced and/or single at the time they are arrested supports other research that they experience more difficulty maintaining relationships and therefore have less potential victims available. Less likely (approximately $25-47 \%$ ) to have their own children. ${ }^{143,171}$

\section{Criminal history}

Minimal if any criminal history, almost $83-90 \%$ do not have previous sex or other convictions. ${ }^{123-158}$ However, other researchers found that sex offenders in general tended to have a prior criminal history, though substance use crimes were the most common. ${ }^{172}$ Approximately $12-60 \%$ of the prior criminal histories involved sex offenses against a child $123,135,172,173$ though most previous convictions were typically non-sexual in nature. ${ }^{105,156}$ This is in contrast to the findings of others. ${ }^{151}$ Approximately $50-85 \%$ of online offenders (soliciting children or child porn) admit to having committed a undetected contact offenses against a child. ${ }^{123,173}$ Merdian et al., ${ }^{174}$ found that nearly $40 \%$ of their sample self-reported contact victims though only nearly $3 \%$ were identified via criminal conviction data. More diversity in offending histories. ${ }^{140,175}$

Criminal history, especially violent offense history was a significant predictor of all types of future offending as is young age at time of first offense. Child porn offenders were not very likely to reoffend once caught. ${ }^{173}$ About $25 \%$ of the child porn offenders reoffended while in supervised release, approximately half involving being alone with children or downloading child porn. ${ }^{175}$ Other violations included use of alcohol, failing to report as direct- all indicating a willingness to ignore rules and to engage in potentially risky behavior. Offenders with a prior history of violation of conditional release were more likely to offend, violently and nonviolently. Of those offenders who had no prior sex offense convictions but admitted having contact victims, they had the most victims. ${ }^{135}$ More likely to confess to police. ${ }^{169}$ Many of the child porn offenders with the most contact offenses went undetected at least in part to their not having a criminal history and skills at grooming. ${ }^{155}$

\section{Psychology}

Some studies suggest no difference between child porn users and contact offenders. ${ }^{127}$ Henry et al., ${ }^{167}$ differentiated three types of child porn offenders:

a. Those with lower self-esteem;

b. Those who are emotionally inadequate (no offense supporting beliefs, low self-esteem, under-assertiveness, and emotional loneliness); and

c. Those who are deviant (low self-esteem, greater emotional loneliness, and greater propensity for cognitive distortions, lack of victim empathy, cognitive and emotional congruence with children).

Child porn offenders tended to demonstrate more psychological problems, depressive symptoms, obsessive-compulsive disorders, low self-esteem, personal distress, frequent masturbation, and greater sexual deviance than contact offenders. ${ }^{176,177}$ No difference between child porn only and contact offenders in regards to depression or anxiety disorders. $20-41 \%$ reported mental health problems. ${ }^{125,156}$ Online and offline child sexual offenders both had problems with loneliness or self- esteem and similar educational levels ${ }^{126}$ though others disputed that child porn offenders experience lower self-esteem or greater emotional loneliness. ${ }^{126}$ Interpersonal difficulties are common (e.g., under-assertiveness, low dominance and warmth, little empathy in relationships, emotional loneliness, problems related to impression management, troublesome interpersonal functioning). Presented with social deficits and often present with a "passive viewer" attitude regarding their offending behavior. ${ }^{169,178,179}$ Some cluster A traitsfeeling misunderstood by others and being isolated and somewhat withdrawn. Child porn users present with high intimacy deficits. ${ }^{174}$ Some evidence suggests less problems (e.g., higher self-esteem, fewer socio-affective problems, less personal distress, lower external locus of control, less criminality and less antisocial behavior). Others found that child porn offenders had more socio affective problems (less assertive, less dominant, less socially confident, less emotional 
regulation. ${ }^{140,149,152}$ Child pornographers have higher degrees of social functioning. ${ }^{9}$

Antisocial orientation was found to be a significant factor for child porn offenders by some researchers whereas others found antisocial orientation was not a significant factor. ${ }^{125,126,131,145}$ Lower rates of cognitive distortions, impression management issues, and less emotional congruence with children than contact offenders. ${ }^{126}$ Child porn users tended to have more sexual self-regulation problems, ${ }^{180}$ others found the opposite. ${ }^{146}$ Less likely to have been the victim of childhood sexual abuse than other offenders (approximately 11$26 \%$ ). ${ }^{9} 156$ Others report that $25-50 \%$ reported being the victim of childhood sexual abuse. ${ }^{104,156}$ Their cognitive distortions may be more related to sex offending in general than to child porn. Utilize indirect means for obtaining sexual and social stimulation. ${ }^{174}$ Online only offenders help avoid and alleviate real world stress via their online environment or online contact while maintaining social distance. ${ }^{20,170,174}$ Substance use likely an issue for approximately $13-60 \% .{ }^{125,156}$ However, others found that substance abuse was not a significant factor for most child porn offender or contact offenders. ${ }^{126,181,182}$

Some research suggests that because of the online-only offenders increased empathy and fewer cognitive distortions that they are less likely to offend with a contact offense against a child, and that they would engage in sexual contact with an adult if available. ${ }^{126,140,147,149}$ However, other studies suggest the opposite ${ }^{151}$ again $50-85 \%$ of child porn only offenders admitted having contact victims that have not yet been detected, many having multiple victims. ${ }^{123,173}$ Following the Model of Potential Problematic Internet Use: ${ }^{173}$

a. Cognitive distortions not only promote problematic behavior but may cause a progression to contact sexual offenses.

b. Specific risk factors include early sexual experience (usually by age 10), sexual preference for children, and Internet characteristics (e.g., anonymity, cognitive-social factors such as less contact with people in offline world). Female child porn offenders tended to demonstrate lower levels of neuroticism and more pleasure-seeking urges and disregards social values. ${ }^{161}$

\section{Paraphilia}

Nearly $80-90 \%$ of child porn only offenders continued to offend (use child porn) while in treatment and after treatment. ${ }^{9,183}$ One study found that nearly all of the child porn only group were actually preferential type offenders ${ }^{4,13}$ and collected porn with themes suggesting children as their primary preference, had a history of collecting porn, previous and current contact offenses, and communicating with like-minded individuals, and they commonly had child porn that was both explicit and non-explicit (clothed pictures). ${ }^{155}$ Some found that possession of child porn was a valid indicator of Pedophilia (though the researchers did not specify whether the offender was only sexually attracted to prepubescent children or to children and adults). ${ }^{123,145,177}$ However, not all child porn users are Pedophile. It was found that approximately $25 \%$ of Internet offenders were Pedophilic; $50 \%$ were diagnosed as Paraphilia NOS (not otherwise specified, which likely includes situational child molesters who do not have a primary sexual attraction to children or may not have any sexual attraction to children and offend sexually against children for nonsexual needs). ${ }^{13,125}$ Others found that the Child Porn Only offender to be more likely homosexual and Pedophilic than other child sex offenders. ${ }^{143,184-186}$ Higher rates of sexual deviancy and deviant sexual arousal. ${ }^{126,143,156}$

Child porn users were more likely to report Hebephilia or Haebephilic (sexual attraction to adolescents) than Pedophilia. ${ }^{147}$
Child porn offenders tended to demonstrate features of Voyuerism and Exhibitionism, frequent masturbation, and greater sexual deviance than contact offenders. ${ }^{124}$ Less emotional congruence with children, had higher victim empathy, and healthier attitudes towards general sexual assault (e.g., did not have rape supporting beliefs). ${ }^{126,143,149,167,187}$ Others found that child porn offenders demonstrated greater cognitive distortions (minimized harm to victim, beliefs that children were sexually willing). ${ }^{151}$ Some Pedophiles may not offend due to being troubled about their desire to have sexual contact with children and are scared of inability to control their sexual arousal. Frequent masturbation and greater sexual deviance than contact offenders. ${ }^{124,176}$ However, Child Porn Offenders may score LOW on risk assessment tools. It should be noted that new tools are being developed and standardized. Many offenders believed that:

a. Their behavior was uncontrollable in reference to use of child porn;

b. Expressed cognitions portraying sex abuse of children as acceptable under certain circumstances; and

\section{c. That they view the world as hostile place.}

Perhaps the child porn offender justifies their behavior because the children are depicted as laughing or enjoying the sexual contact and that they are not directly sexually abusing the child. For the pedophile who is child porn user easy access to material makes it more difficult to control urges.

\section{Porn collection}

Typically, people look at porn that matches their sexual interest. ${ }^{169}$ The porn collection is the single best indicator of what the offender wants to do, but not necessarily what he has done. ${ }^{4}$ The specificity of the pornographic material appears to be a stronger indicator of sexual preference than actual sexual contact. ${ }^{177}$ Child porn may be collected by non-pedophiles and pedophiles; many pedophiles find explicit child porn disgusting and therefore prefer non-nude pictures. ${ }^{188}$ Most viewed both male and female pictures (likely due to the availability of images versus preference). ${ }^{148,149,153,156}$ Tended to possess greater amount of child porn. ${ }^{169}$ Wider range of ages in child porn. ${ }^{169}$ Paying for access to child porn; ${ }^{169}$ Regularly deletes their child porn images. Tends to possess child porn depicting no sexual activity, nonpenetrative sexual activity between children or solo masturbation, or nonpenetrative sex between child to child or between child and adult. ${ }^{134}$ Tended to have more extreme porn, suggesting that they prefer a wider range of sexually explicit material online ${ }^{189}$ while others found only a small number downloaded extreme pictures. ${ }^{148}$ May depersonalize pictures and view as commodity to be collected and traded.

Motivation for child porn use must be considered because different child porn users use and collect child porn for different reasons, not all sexually motivated or sexually motivated alone. Therefore, the porn use and/or collection represents the offender's likes and fantasy. ${ }^{104,139,186-191}$ Some use child porn to relieve sexual tensions, to escape stress, and/or to indulge sexual fantasies. ${ }^{139,192}$ Use of child porn may help some control sexual deviance while for others facilitates acting on preexisting fantasies and urges. ${ }^{179}$ However, viewing deviant material may stimulate existing fantasies and low inhibition leading to contact offenses. ${ }^{179}$ Repeated viewing of child porn and/or contact with other offenders may weaken resolve leading to contact offense even finding child porn accidentally while searching for regular porn impacts potential for continued child porn use and perhaps to contact offenses. Many offenders engaged in contact offenses prior to use of child porn with lower rates of future offending. 


\section{Solicitation offenders}

These offenders solicit victims online though may or may not use child porn. Some will keep their sexual offense behavior and contact limited to online only. Others will move to meet in person with the victim. The fantasy-driven offender restricts the sexual interactions to online activities and the contact-driven offender meets the victim online and then in person to engage in sexual and physical contacts. ${ }^{2}$ The fantasy-driven offender has also been referred to as the cybersexual offender. ${ }^{2,193-195}$ These offenders limit their offending to online interaction with the minors. These offenders are not motivated by a desire to engage in physical contact with the victim. Kloess et al., ${ }^{195}$ highlight the danger of the fantasy-drive/cybersexual offender in that the dynamic nature of the offender's motivations may change in any given situation or perhaps at times the offender may have contactdriven motivations when usually they do not. Therefore, the fantasy driven/cybersexual offender may at any time change their sexual motivation to include contact- driven thoughts and therefore engage in physical and sexual contact with the children as demonstrated in the literature. ${ }^{195,196}$ The seriousness of the sexually exploitive interactions with minors is a serious form of abuse regardless of whether offline physical and/or sexual contact occurs.

Lastly, the distinction between contact and fantasy (solicitation) offenders is difficult to ascertain. Both groups engage in online behaviors that provide the offender with sexual gratification and can easily lead to offline contact. ${ }^{197}$ Based on a review of the literature, many if not most online solicitors will likely become dual or contact offenders, or mixed offenders. The Mixed-Offender offender engages in both online and offline solicitation and sexual abuse. ${ }^{193,197}$ Sexual grooming is the shared pathway for these offenders. ${ }^{169}$ Motivations and subsequent offender behavior are often motivated by the victim's response and compliance which could easily lead to increased fantasy/ contact driven behavior. ${ }^{194}$ The intensity of the online relationship and the desensitization of victims to sexual content appeared to be main factors for those who engage in offline sexual contact with the victim, though both online and offline sexual gratification of the offender is sexually abusive to the victim. ${ }^{196}$ Again, DeHart et al., ${ }^{193}$ found that offenders tend to escalate their sexually abusive behavior rapidly.

\section{Demographics \& education}

More likely to be Caucasian; about $10 \%$ not Caucasian. ${ }^{126}$ Younger than contact offenders. ${ }^{126}$ Average age $35-39,{ }^{3,126}$ with offenders ages ranging from 19 to $64 .{ }^{3}$ One study showed that $16 \%$ of their offenders were age 50 or older. ${ }^{3}$ High education than contact offenders. ${ }^{147}$ Other data suggests that online and offline child sexual offenders were found to have similar educational levels as other criminals. ${ }^{126,198}$ Most victims of online solicitation were between the ages of $13-17 .^{3,199}$ Most offenders were male. ${ }^{3}$ None represented themselves as being children or adolescents though all portrayed themselves as being younger. ${ }^{3}$ Other studies found that $5-33 \%$ posed as minors. ${ }^{200}$ Offenders tended to target victims within a close geographical proximity, ${ }^{3}$ which suggests their intent to meet with the victim in person. Second most likely group to reside with children after contact offenders. ${ }^{147}$

\section{Employment status}

More likely to be professionals, majority white-collar, ${ }^{201}$ though Alexy, Burgess et al found the opposite.

\section{Relationship status}

More likely to have never lived with a lover than contact offenders. ${ }^{147}$ More problems with capacity for relationship stability than child porn or contact offenders. ${ }^{147}$ Less likely to have lived with a child. ${ }^{147}$

\section{Criminal history}

Unlikely to have a criminal history ${ }^{201}$ while others found the approximately $13 \%-70 \%$ had prior sex offenses. ${ }^{163}$

Criminal histories the same as child porn offenders. ${ }^{147}$ Less likely to admit to undetected sexual offenses than contact or child porn only offenders. ${ }^{147}$ May have history of contact offenses, but once adjudicated, tend to recidivate with contact offenses at a low rate though may continue with contact online. ${ }^{147}$ Most solicitation offenders were contact-driven and therefore dual offenders., ${ }^{2,147}$ Antisociality appears necessary to engage in sexual contact with minors. ${ }^{143,174}$ and is one of the strongest differentiating factors between contact/dual offenders and online or child porn users.

\section{Psychology}

Online and offline child sexual abusers both had problems with loneliness or self-esteem and similar educational levels. ${ }^{126}$ Scored lower on impression management. ${ }^{126}$ Likely to have substance abuse/ use issues. ${ }^{147}$ Histories of an adversarial childhood environment and specifically having been the victim of childhood sexual abuse was a significant predicator of contact sexual offending. ${ }^{174}$

\section{Paraphilias}

None of the solicitation offenders had victims under age 12, average age $13-15 .{ }^{202}$ Less likely to report Pedophilic interests; ${ }^{147}$ More likely to report Hebephilia or Haebephilic (sexual attraction to older adolescents) than Pedoplila. ${ }^{147}$ Demonstrated emotional congruence with children. ${ }^{147}$ Some fantasy-driven solicitation offenders had more extreme child porn (e.g., younger ages, higher levels of sexual explicitness) in combination with increased social involvement with other child porn users. ${ }^{.74}$ Demonstrated more cognitions justifying sex with children and a more of a sense of sexual entitlement than child porn/noncontact sexual offenders. ${ }^{174}$ Demonstrated greater empathy for victims (if behavior is kept online only). ${ }^{126}$ Demonstrated higher sexual deviance. Similar grooming process as contact offenders restrict sexual interactions with minors to online activities. ${ }^{147}$ Other research suggests more go on to online contact with victims and/or on to contact offending. For the contact-driven offender, most cases involved multiple contact with the victims and involved engaging in sexual intercourse. ${ }^{202}$ Most engaged in sexually explicit chat ${ }^{203}$ only a few involved coercion or violence and were similar to statutory rape cases. $^{202}$

Victim believes they are involved in a romantic/sexual relationship with offender. ${ }^{202}$ More likely than contact offenders to have viewed child porn. ${ }^{147}$ Less likely to have male victims than contact offenders. ${ }^{147}$ Reported lower sex drive/preoccupation. More likely to have unrelated or stranger victims than contact offenders. View online profiles to find victims, utilize chat rooms, about $25 \%$ engage in solicitation offenses. Engaged in sexual chat, exchange porno photos, some lie about age portraying themselves as younger, but most indicated that they were adult..$^{147,202}$ No difference than contact offenders in terms of dangerousness. ${ }^{204}$ Grooming tended to be based on victim accessibility, opportunity, and the victim's perceived vulnerabilities, possibly victim attractiveness though not as likely. ${ }^{205}$ Most online offenders visited online chat rooms geared toward minors and most read the victim's profile. Most victims were aware that they were communicating with an adult and indicated that they were 
expecting sexual activity to occur and most had sex contact on more than one occasion with the offender. Most made their sexual intentions clear immediately (approximately within first 35 minutes). ${ }^{206,207}$ The majority of offenders and victims exchanged sexually orientated pictures the first day. ${ }^{3}$ This may help desensitize the victim. Most offenders appear to be contact driven versus fantasy driven. ${ }^{3}$ Over $80 \%$ initiated telephone and email contact with the victim. Many of the grooming occurred to allow for in person contact within 3 days ${ }^{208}$ whereas others take their time to develop the relationship. ${ }^{128,209}$ Some have sexual online user names.

The online offender often chose victims who had sexual content in their profile, assessed the victim's perceived neediness or submissiveness, focused on victims whose profiles contained the victim's age, and when the victim had young-sounding usernames. Many offenders are in contact with multiple victims at the same time. ${ }^{3}$ The contact offenders often brought items to the meeting with the victim indicating their intent to be sexual with the victim. ${ }^{163}$ Average communication lasted approximately 25 days. Most attempted an offline, contact meeting with the victim. Though extra-familial child molesters had lower recidivism after age $50,{ }^{210}$ this group of offenders does not appear to age-out. ${ }^{3}$ Online only offenders help avoid and alleviate real world stress via their online environment or online contact while maintaining social distance..$^{20}$

\section{Porn collection}

About half had extensive porn collections, though only a small number possessed child porn. Others found that $41 \%$ had child porn. ${ }^{163}$ More likely to have viewed child porn than contact offenders. ${ }^{147}$ Fantasy-driven offenders tended to collect images of child posing in erotic ways but involving no sexual activity or the child engaging in solo masturbation. ${ }^{134,169}$

\section{Dual offenders}

The dual offender engages in online use of child porn and engages in actual physical/sexual contact with the victim. This includes the fantasy-driven solicitation offender once the offender attempts or engages in physical contact with the victim. Both situational and dispositional factors apply to the dual offender. ${ }^{8,84,211,212}$ This implies that a continuum of factors is involved in an offender's decision to actout. In addition, it is difficult to distinguish clearly defined categories of child porn only offenders and those who solicitate or engage in offline contact, as many of the child porn only offenders were later found to have contact offenses and most self-reported sexual contact offenses that were undetected. I would also profer that the MixedOffender offender, who engages in both online and offline solicitation and sexual abuse, ${ }^{197}$ is similar to the dual offender in that even if they do/do not use commercial child porn, they make child porn as they engage in the online sexual contact. Sexual grooming is the shared pathway for these offenders.

\section{Demographics \& education}

Less likely to have completed high school. ${ }^{168,213}$ Tend to be older. ${ }^{149,156,169}$ Others found that they tended to be younger

\section{Employment status}

Most were unemployment. ${ }^{168,213}$ They often hold positions of trust and power through employment or volunteering activity. ${ }^{135}$

\section{Relationship status}

Just over half of internet-contact offenders were single or never married $^{168,213}$ or live on their own. ${ }^{169}$ Both child porn users and solicitation offenders (online soliciation only) were more likely to never have lived with a lover and solicitation offenders were more likely to report Hebephilia or Haebephilic (sexual attraction to older adolescents) than Pedoplila. ${ }^{147}$ More likely to live with a partner and their partner's child. ${ }^{134}$ Tended to have access to children ${ }^{169}$ Living arrangements involved living with parent and partner's child but not own biological child). ${ }^{169}$ Ability to engage in establishing a trusting relationship with both adults and children. ${ }^{129,134,156,173}$ Engage in the sexual grooming of the victim. ${ }^{169}$

\section{Criminal history}

More likely to have criminal histories compared to noncontact offenders. ${ }^{134,140,169}$ Antisociality appears necessary to engage in sexual contact with minors ${ }^{11,143,174}$ and is one of the strongest differentiating factors between contact/dual offenders and online or child porn only users. Approximately $16 \%$ of the dual offenders had a prior sex offense involving a child ${ }^{169}$ or other sex crime. These findings were in line with other studies. ${ }^{173}$ Dual offenders presentated with both deviant sexual interests and anti-social orientation (e.g., antisocial cognitions, sexual and/or nonsexual criminal history, including violent offenses; more than 3 prior offenses on average) ${ }^{169,173}$ More likely to have undetected sex offenses.

\section{Psychology}

Higher rates of antisociality than child porn and contact offenders ${ }^{145}$ some found same/similar levels of psychological disorders between the child porn offender, dual offender, and contact offenders. ${ }^{145}$ Online and offline child sexual abusers both had problems with loneliness or self-esteem and similar educational levels. Were more likely to present with a history of illicit drug use; Focus on public image (impression management). ${ }^{135}$ Are able to hide within the community. ${ }^{135}$ Ability to identify vulnerable children. ${ }^{169}$ Less victim empathy and more cognitive distortions about the legitimacy of the sexual contact. ${ }^{126}$ They likely engage in sexual grooming and have access to children. More likely to report having been the victim of childhood sexual abuse. ${ }^{214}$ Histories of an adversarial childhood environment and specifically having been the victim of childhood sexual abuse was a significant predicator of contact sexual offending. ${ }^{174}$ Some offenders charming, able to easily groom potential victims, appear sincere, compassionate, morally sound, and socially responsible. ${ }^{135}$ One example of this type of offender would be Jerry Sandusky.

\section{Paraphilia}

High rates of sexual deviance. ${ }^{145}$ Engages in sexual grooming. ${ }^{169}$ One study found that $17 \%$ of the dual offenders admitted using child porn either prior to or during their sex crimes. ${ }^{215}$ Child porn age preferences within 6 year range. ${ }^{169}$ More likely to be diagnosed as having Pedophilia; others have found no difference between contact and noncontact offenders for the diagnosis of Pedophilia. ${ }^{124}$ Dual offenders were the most likely to be Pedophilic or Hebephilic. ${ }^{143}$ smaller number of travelers were situational offenders verses preferential and may not have any child porn collection. ${ }^{155}$ One study found that nearly $50 \%$ of the dual offenders were sexually attracted to both children and adults, still meeting the criteria for Pedophilia. At the very least, the offender would meet the diagnostic criteria 
for Paraphilia, Unspecified. When travelling to meet with a victim, most brought a rape kit (e.g., lubricant, condoms, sex toys) and at least half brought a camera suggesting either to seduce the child into posing or to take picture or video the sexual activity/contact. Most had established a boyfriend/girlfriend relationship with the victim. ${ }^{155}$

\section{Porn collection}

Likely to possess child porn. ${ }^{169}$ For the Pedophile who is a child porn user easy access to material makes it more difficult to control urges. Generally does not pay for child porn; ${ }^{169}$ Child porn production often involves pictures/videos of their own sexual activity with their victims. ${ }^{155}$ Child porn offenders collect images from mild to extreme in nature, however, dual offenders tended to collect images involving non-penetrative and penetrative sexual activity between a child and adult while noncontact offenders tended to collect images of child posing in erotic ways but involving no sexual activity or the child engaging in solo masturbation. ${ }^{134,169}$

\section{Percentage of child porn offenders who are dual offenders}

At the time of arrest and prosecution, many child porn only offenders have no known criminal histories involving contact sexual offenses against children. However, the literature demonstrates that many do in fact have contact sexual offenses against children that were undetected. $26-85 \%$ of child porn only offenders admitted having contact sexual offenses against children that were undetected ${ }^{4,123,131}$ approximately $20-25 \%$ of investigations for child porn crimes uncover contact child sex crimes. ${ }^{135}$ Nearly $40 \%$ of child porn only offenders engaged in other contact child exploitation and the viewing of online child porn may have served to strengthen a strong predatory pattern of behavior. ${ }^{199,216} 25 \%$ of child porn offenders had at least 1 victim, however, several had many victims. ${ }^{135}$ Child porn offenders with histories of prior contact sexual offenses against children were the most likely to reoffend. ${ }^{105}$ Use of polygraph is essential to ascertain if the child porn offender has contact victims. ${ }^{123,216}$

\section{Contact offenders}

The contact offender does not generally engage in the online use of child porn nor solicit victims online. They engage the victim in the community.

\section{Demographics \& education}

Less likely to have completed high school and less educated compared to other groups. ${ }^{126,142-147,158}$ Other data suggests that online and offline child sexual offenders were found to have similar educational levels as other criminals. ${ }^{126,198}$ Child sexual abuse offenders (contact offenders) were older than child porn offenders and more often caught ${ }^{126,140,149,156,158}$ although others found that contact offenders were younger. ${ }^{147}$ Approximately $70 \%$ are Caucasian ${ }^{144,152,154,156}$ Contact offenders tended to have access to and likely supervision of children (e.g., child of their partner, family, or neighborhood). ${ }^{169}$ Most likely to reside with children. ${ }^{147}$

\section{Employment status}

Less often employed. ${ }^{140,149,156}$ Others find most are employed. ${ }^{198}$

\section{Relationships status}

Tend to be in a relationship. ${ }^{105,126,142-148,171}$ Contact offenders more likely to reside with a child ${ }^{147}$ and were more likely than child porn offenders to have their own children. ${ }^{105,142,143,148,171}$ They have better relationship stability and few relationship difficulties. ${ }^{147}$ Child sexual abusers/contact offenders were more likely to be involved in an intimate relationship than child porn only offenders. ${ }^{168}$ About 50\% divorced or separated.

\section{Criminal history}

High rates of antisociality. ${ }^{145}$ Antisociality appears necessary to engage in sexual contact with minors $\mathrm{s}^{11,143,174}$ and is one of the strongest differentiating factors between contact/dual offenders and online or child porn users. Were more known to the criminal justice system than child porn only offenders. ${ }^{140,149,156}$ Some have prior sex offenses. Approximately $40 \%$ engaged in cruelty toward animals compared to nearly $70 \%$ of rapists. ${ }^{97}$

\section{Psychology}

Online and offline child sexual offenders both had problems with loneliness or self-esteem, emotional deficits, depression, and anxiety disorders and both groups had similar educational levels. ${ }^{126,217}$ Some found same/similar levels of psychological disorders between the child porn offender, dual offender, and contact offenders. ${ }^{145}$ Lower degrees of social functioning. ${ }^{168}$ Child sexual abusers reported almost twice as likely to have been victim of childhood sexual abuse vs child porn users but both groups higher than non offending population, ${ }^{168}$ with approximately $70 \%$ or higher reporting childhood sexual abuse. ${ }^{21,97,174,218,219}$ Histories of an adversarial childhood environment and specifically having been the victim of childhood sexual abuse was a significant predicator of contact sexual offending. ${ }^{174}$ Approximately $12 \%$ of male childhood sexual abuse victims went on to become sexual abusers. ${ }^{75}$ Family violence, emotional rejection, and abuse by females increased risk for male victims to sexually abuse children. ${ }^{75}$ If sexual abuse occurred, likely neglect, emotional and physical abuse occurred in the family as well. ${ }^{220}$ Substance use/abuse was reported in approximately $28-40 \%$ of cases. ${ }^{148,181,182}$ Most have insecure parental attachments. ${ }^{97}$ Most reported early exposure to pornography (prior to age 10). ${ }^{97}$ Most reported onset of early masturbation (before age 10). ${ }^{97}$

\section{Paraphilia}

Less likely to demonstrate deviant sexual arousal. ${ }^{145,147}$ Less likely to admit to Pedophilia or Hebephilia. ${ }^{147}$ Higher rates of male victims. ${ }^{147}$ Demonstrated less empathy toward the victim. ${ }^{126}$ Demonstrated more cognitions justifying sex with children and a more of a sense of sexual entitlement than child porn/noncontact sexual offenders. ${ }^{174}$ Grooming tended to be based on victim physical attractiveness, ease of access, and perceived vulnerabilities., ${ }^{4,209,221}$ Contact offenders tended to use deviant sexual fantasies and masturbated to these fantasies before and after their first and subsequent sexual contact offenses with children. ${ }^{222}$ The deviant sexual fantasies increased following the first contact sexual offense against children. This supports the conditioning process of deviant fantasies and behavior. Child contact sex offenders tended to differ from child porn only offenders related to cognitions of children as sexual beings; no differences found on offense justifications. ${ }^{151}$ Approximately $40 \%$ reported engaging in bestiality. ${ }^{97}$

\section{Porn collection}

Larger collections sometimes found with contact offenders (themed porn). Less likely to have viewed child porn than child porn offenders. ${ }^{20}$ Not the number per se of images that matters, but the type and severity of the material- images of explicit sexual contact more indicative for contact offenses. The porn collection is likely to involve the offender's sexual interest and preference. The porn collection is the single best indicator of what the offender wants to do, but not necessarily what he has done. ${ }^{13}$ 


\section{Juvenile sex offenders with minor victims}

Although this article is focusing on the adult sex offender, it appears worthy to briefly address the juvenile sex offender who has minor victims. The following is a summary taken from Finkelhor et $\mathrm{al}:{ }^{198}$

a. Approximately $36 \%$ of those who sexually molest minors are juveniles.

a. Juveniles who sexually offend against children are more likely to do so in groups or at schools than adult offenders.

b. Juvenile sex offenders are more likely to have male victims.

c. Juveniles sex offenders are more likely to have younger victims than adult offenders.

d. Between 12-14 years of age, the juvenile sex offender appears to surge in sex offense behavior and then plateaus for offense against younger children and then surges for adolescent victims. 1 out of 8 of the juvenile offenders are younger than age $12.7 \%$ of the juvenile sex offenders are female, Deviant sexual preferences appear to play less of a role than for adult sex offenders. Sexual curiosity appears to be the primary motivation. Poor judgement, compulsive behavior, and other mental health problems are likely. $85-95 \%$ of the juvenile sex offenders had no criminal history.

\section{Summary of the differences between the child porn offender, the dual and contact offender}

In summary, most researchers have found more similarities than differences between the child porn offenders and the dual and contact offenders. ${ }^{168}$ Again, the limitatyions of many studies resulted in difficulty clearly distinguishing any of the types of offenders, all may use child or adolescent porn, all may engage victim's online. It was found that differences between the child porn offender, contact and dual offender primarily focused on offending characteristics, with few differences on demographic and mental health features. ${ }^{145}$ Child porn offenders tend to have far less antisociality than dual or contact offenders. ${ }^{145,177}$ The child porn offender, dual and contact offender differed in three key factors: antisocial traits, sexual deviance, and opportunity to offend offline or online. ${ }^{143}$ Child porn offenders had lower rates of general, violent and sexual offending than either of the other two groups. ${ }^{14}$

Specifically, in reference to deviant sexual arousal, the dual offenders were most likely to demonstrate both Pedophilic and Hebephilic interests, the child porn offender was next, and the contact offenders were least likely to demonstrate Pedophilic or Hebephilic interests. Child porn only offenders who present with similar characteristics of dual and contact offenders (e.g., lower education, offending histories including persistent sexual and violent offenses, and high levels of sexual deviance) are perhaps at higher risk for crossover offending. ${ }^{145}$ Dual and contact offenders are similar and those contact offenders who use child porn may be driven by increased deviant sexual interests (e.g., child porn). ${ }^{145}$ Aside from this difference, the similarities between the dual and contact offender appear strong.

\section{Shared factors of child porn only \& child sexual abusers/contact offenders for violent and sexual recidicism}

The following are significant predictors of violent and contact sexual recidivism among child porn offenders and child sexual abusers included:

i. Offender age at time of first offense (young age).

ii. Prior offense history including violent offenses. ${ }^{173}$

iii. Failure of conditional release.

iv. Lower education.

v. Being single.

vi. Having non-internet child porn (home-made).

vii. Prior sex offender treatment (maybe not treatment but rather prior sex offense history that required treatment).

viii. Having pictures of children (under 12; not of adolescents).

ix. Substance use. ${ }^{173}$

x. In general, the risk factors for violent and nonviolent sexual and nonsexual reoffense were the same for all sex offenders, including those with adult victims and included criminal history (sexual or nonsexual), substance use problems, and self-reported sexual interest in children predicted both sexual and nonsexual reoffense. ${ }^{173}$ The sex offender's nonsexual criminal offenses were often sexually motivated.

\section{The undetected offender}

For those child porn or solicitation offenders who had no known contact offenses: ${ }^{168}$

i. Undetected child sexual abusers tended to be:

a. Younger;

b. More educated;

c. Employed;

d. Less reported histories of childhood sexual abuse; and

e. Presented with less socio-affective deficits which suggests less childhood maltreatment and more secure parent-child relationships.

ii. Undetected child sexual abusers scored lower on emotional coping/problem solving difficulty (they may be better at problem solving effectively). ${ }^{168}$

iii. Undetected pedophilic and hebephilic pornography and mixed offenders- more than half reported co-occurring paraphilic content during masturbation; co-occurring paraphilias were associated with higher scores addressing sexual selfregulation problems (e.g., higher rates of masturbation, sexual preoccupation), more paraphilias, and antisocial attitudes and behavior. ${ }^{168}$

iv. Undetected child sexual abusers, child porn offenders, and detected child sexual abusers did not demonstrate any significant difference on abuse supporting beliefs, emotional deficits, or loneliness. ${ }^{168}$

v. Perhaps the detected child sexual offender who reports childhood sexual abuse may do so to justify their offense behavior by blaming adverse childhood experiences thereby reducing cognitive dissonance in offending. This may also be used to manipulate the criminal justice system to portray self as a victim. ${ }^{168}$ Determining whether they were or were not sexually abused as children is difficult. Many recant that claim after adjudication. 
vi. Sexual preferences and sexual preoccupation appear to be underestimated in sample of detected offenders. ${ }^{168}$ This may be addressed by more thorough assessment that involves sexual arousal/interest specific testing as well use of polygraph.

\section{Recidivism \& crossover}

a. Some studies claim that those who are arrested for engaging in child porn only offenses with no known history of contact offenses, are at low risk for crossing over to contact offenses, though they may recidivate with online child porn. ${ }^{223}$ However, most of the data was per the offender's self-report and a follow-up period of only approximately $2 \frac{1}{2}$ years. Again, however, approximately up to $85 \%$ of child porn only offenders self-report undetected sexual abuse victims.

b. The accessibility of child porn online may serve as a safe place to explore deviant sexual interest and likely helps to lower inhibitions against sexual contact with children or at the very least making the sexualization of children more acceptable. This may lead to contact offenses. ${ }^{224}$

c. Larger child porn collections found with contact offenders which may help to accept voyeuristic behavior (e.g., viewing porn) and then masturbating at home to the child porn while believing that they are not hurting the child. ${ }^{146,151}$

d. One study found that $17 \%$ of the dual offenders admitted using child porn either prior to or during their sex crimes. ${ }^{215}$

e. All of these lessen inhibitions: antisocial behavior, lack of victim empathy, and cognitive distortions supporting sexual contact with children

f. Fantasy-only group-are at higher risk for crossover if connecting with like-minded offenders

g. Most important- a willingness to have sexual contact with children.

h. Having access to children offline makes it easier to engage in offline sexual contact and they often choose victims that are easy to access.

i. Having minimal or no offline non abuse support people increases the likelihood of crossover to contact offending.

j. A preference to or sexual arousal to children increases the likelihood of crossover. ${ }^{225}$

k. Additional factors related to crossover to contact offending include substance abuse, antisocial orientation, deviant sexual interests, and situational factors related to Internet sexual activity.

1. Time spent online and number of child porn images collectedmore time online generally lead to more deviant and severe child porn- correlated with contact offenses; imagery was not enough after some time.

m. Prolonged time online lead more to habituation and increases need for more severe porn.

n. Interacting with other child pornographers increased likelihood of contact offense.

o. May lead to cybersex with children online (solicitation offender) as well as contact with the victim offline.

It is important to understand that those who crossover to engaging in solicitation or contact offenses have strong beliefs that either engaging online or in person with children is acceptable and not actually harming the child or perhaps they have the belief they have the prerogative to do so. Fueling deviant interests, thoughts and actions (e.g., viewing or masturbating to child or deviant porn) serves to further strengthen deviant thoughts and behavior and encourages the offender to want to try the actual behavior viewed or to engage in contact offenses. The unknown factor is if and when the offender makes the conscious decision to engage in contact offense behavior, most of which will not likely be detected for some time, possibly allowing for numerous children to be victimized. Again, previously mentioned literature suggests that $50-85 \%$ of child porn only offenders admitted to having engaged in contact offenses (undetected) and that they tend to self-report having more than one victim that they have not yet been caught for.

\section{Child porn possession cases}

Again I want to reiterate that child porn users may collect adolescent and adult porn as well. It is unclear in the research as to whether the term "child porn" includes or exclude those offenders who have primarily adolescent porn. It is assumed that the term "child porn" involves any minor. The Internet offers 3 things to make the use of online porn convenient:

a. Accessibility- 24-hours per day, every day, it is available anywhere Internet is available;

b. Affordability- most porn websites offer samples of free porn images and short video clips. If an offender wishes to purchase more of a specific type of porn material, they can pay a fairly reasonable fee to access more deivant material;

c. Anonymity- unless being monitored by law enforcement or other agencies, the person may surf the Internet without revealing their identity.

Even with online chat rooms and other contact sites, the offender can easily mask their true identity. ${ }^{170}$ The content of the child porn and the offender's behavior in the contact offense were similar in theme. ${ }^{135}$ This suggests what I refer to as Practice and Premeditation. Practice because the offender uses the porn to strengthen deivant sexual and/ or aggressive fantasies and even rehersing how to re-enact the fantasy in real-life. Premeditation because of the planning and fantasizing that occurs prior to initiating contact with the victim. This is applicable to any porn, child or adult. Research also supports that the offender's child sexual related fantasies and contact offending behavior (e.g., modus operandi) were related. . $^{179,222,226,227}$

Child porn offenders collect images from mild to extreme in nature, however, dual offenders tended to collect images involving non-penetrative and penetrative sexual activity between a child and adult while noncontact offenders tended to collect images of child posing in erotic ways but involving no sexual activity or the child engaging in solo masturbation. ${ }^{134,169}$ For both contact and noncontact offenders, there were no differences found in the gender of the children involved in the child pornography or the average age of the children. ${ }^{134}$ However, dual offenders demonstrated a preferred age range of children in the child porn images. ${ }^{134}$ This preference for specific age ranges suggests that the dual offender may have more Pedophilic or Hebephilic interests that have not been adequately assessed except by offender self-report.

Additional facts about child porn cases:

d. It requires time and effort to collect and organize pornography. ${ }^{214}$ 
e. Some hypothesize that the offender spends time organizing and sorting the porn to maintain a sense of control when feeling out-of-control as well as to improve depressed $\operatorname{mood}^{228}$ and for some it may ease stress or help to avoid dealing with difficult emotional states. ${ }^{189}$

f. Most possessed images of children under 12 and most involved vaginal/anal penetration of the child. ${ }^{155}$ Offenders may also possess adult porn. This may be done because:

g. The offender is not preferential

h. The offender may have other paraphilic interests involving adults

i. Adult and child porn is often used to groom the child and desensitize the victims to sexual conversations and touch

j. Some of those the offender shares their porn with may inadvertantly include adult porn or the other person may request adult porn as well as child porn. ${ }^{155}$

k. Offenders who collect child porn were often highly selective and their choice of images matched their preexisting sexual fantasies. . $^{11,179,188,229,230}$

1. Noncontact offenders may have both adult and child porn in their collection, whereas contact offenders tend to collect a specific target and preferential age range.

$\mathrm{m}$. Contact offenders were more likely to masturbate to the child porn and save it to an external medium.

n. Some studies report that noncontact child porn users tended to have larger collections than dual and contact offenders, McCarthy found the opposite.

o. Most offenders keep their collection exclusively in electronic/ digital format with only a small number possessing non-digital printed material. ${ }^{155}$

p. Most child porn offenders did not use sophisticated security protocols. ${ }^{155}$

q. The majority seem to communicate online with other likeminded individuals or organizations. ${ }^{155}$ This is likely needdriven. ${ }^{13}$

r. $26-85 \%$ of child porn offenders have multiple child contact victims that were previously undetected. ${ }^{123,131,135,155,173}$

\section{Grooming typologies}

Grooming is the process by which the offender engages the victim to prepare for victimization. Some grooming strategies are direct, involving immediate introduction of sexual conversation, threats, and coercion, while less direct methods are used over time to establish a relationship with the victim. Unfortunately, the later is the most difficult to detect because many of the relationship strategies used appear normal in nonvictim grooming situations. Some offenders move immediately into soliciting sexual contact online or offline thereby skipping the grooming process altogether. ${ }^{193,231,232}$ Several theories of grooming will be discussed. The communication strategies used focus on whether the offender is fantasy-driven (keeping the sexual contact online) or contact-driven (expecting to engage in physical and sexual contact with the victim). ${ }^{2}$ It has been theorized that most online (solicitation) offenders are patient enough to develop relationships with their victim, which can easily eventually move to contact offending. ${ }^{200}$ Several grooming typologies will be discussed.

\section{O'Connell grooming typology 205}

This five stage theory involves:

i. Friendship forming stage;

ii. Relationship forming stage;

iii. Risk assessment stage;

iv. Exclusivity stage; and

v. Sexual stage.

This received some support from Winterset al. ${ }^{3}$ Others found that many offenders may skip the stages of friendship or relationship forming and risk assessment stage and move immediately intro sexual conversation and attempted meeting with the victim. ${ }^{3}$ The progression and order of the stages varied with offenders who followed O'Connell's model. ${ }^{208}$

\section{Black et al. typology}

This is a four-stage theory of persuasion techniques used for both online and offline grooming was proposed by Black and his colleagues. ${ }^{208}$ The four stages are:

i. assessing the target's location;

ii. make plans to meet;

iii. use flattery and compliments; and

iv. Assess target's parents work schedule.

This theory has received some support, though the major limitation is that the theory is primarily based on conversations of volunteers portraying minors versus actual minors/victims, although the literature has demonstrated that the offender guided the contact regardless of whether the offender was talking with a decoy or actual victim $^{206,208,233}$ though because decoy victim do not engage in online sexual behavior (e.g., masturbation, exchanging naked photos) they may cause the offender to back off. ${ }^{193,234}$ The progression and order of the stages may vary depending on the offender.

\section{Staksrud}

Another model for grooming was proposed by Staksrud. ${ }^{235}$ This model has 3 stages. The first is observing the chat rooms as a passive observer. Once a specific victim is identified, the offender initiates communication, encouraging the victim to enter into private chat. The second stage involves grooming behavior and activity. The final stage is engaging the victim in sexually explicit conversations, exchanging sexually explicit photos or videos, and then perhaps initiating a meeting (if in-person contact is attempted or occurs, the offender is now a dual or contact offender). This model has been supported by others. ${ }^{3}$

\section{DeHart et al. typology}

This typology offers four categories: cyber-sex only offenders, cybersex/schedulers, schedulers, and buyers. ${ }^{193}$ The cyber-sex only offenders are fantasy-driven as Briggs et al., ${ }^{2}$ proposed. They engage in sexual chat, expose themselves online and expect the same from their victim, but have no intent at that time to meet the victim in person. Many mention scheduling meetings with the victim but the details were vague and the offenders did not follow through with the meetings. Most are Caucasian. The cybersex/schedulers engage in online sexual behavior, including explicit sexual talk and exchanging 
explicit images/videos. This is the group most likely to demonstrate child-specific or incest interests. They tend to have long interactions with the victim, often lasting several months. They are the group most likely to ask the victim specific questions about the victim's sexual characteristics. These offenders are likely to schedule a meeting with the victim but were the most likely to cancel or not show-up.

The rationale provided by the researchers for why the meeting was not kept include

i. The offender was pretending to be interested in a meeting to maintain victim compliance;

ii. The offender was reluctant or fearing that the meeting was a trap; and

iii. The discussion of a meeting may have simply been a part of the offender's fantasy.

The schedulers are similar to Briggs et al., ${ }^{2}$ contact group. Most are Caucasian though more non-White offenders were in this group. These offenders explicitly sought sexually explicit photos of the victims but rarely exposed themselves. About a third expressed childspecific specific or incest themes. About half of the offenders engaged the victim for only one day, seeking what is referred to as a "hook-up".

These offenders do not attempt to develop a relationship with the victim. The offender's grooming typically involved discussing the victim's sexual experiences, asking about whether the victim has a boyfriend, and within a few chats schedules a meeting. Some of these offenders requested sexually explicit photos to ensure that the victim was real. The buyers are like the schedulers in that their focus is to meet with the victim offline. They are less likely to expose themselves to the victim and only some requested sexually explicit photos from the victim. About a third expressed child-specific or incest themes, and approximately a third interacted with the victim for only a day. The main focus of these offenders is to negotiate sexual favors in exchange for money and may include human traffickers, pimps, and family members offering their children to others for sexual behavior. These offenders are more ethnically diverse. One of the findings of DeHart, research was that online interactions can escalate rapidly. They also supported the findings of Briggs et al., ${ }^{2}$ that decoys versus actual victim online did not change the outcome of the offender scheduling a meeting nor did it appear to hamper the offender's behavior of exposing themselves, seeking sexually explicit photos, or engaging in or encouraging masturbation.

\section{Webster et al. typology}

This typology offers three categories: intimacy seekers, adaptive, and hypersexual. ${ }^{196}$ Intimacy seekers typically do not have prior sex offenses (again, however, most have self-reported undetected contact offenses). These offenders believed that they were involved in an intimate and consenting relationship with the minor. They spent time establishing a relationship and then ensued a contact meeting with the victim. They view the relationship with the victim as consensual and likely did not significantly modify their identity. These offenders tended to be cautious to avoid others becoming aware of their sexual intentions. They were less likely to collect child porn or engage in contact with other offenders online. They spent a significant amount of time communicating with the victim before meeting with them for what they viewed as a "intimate" relationship. The adaptable offender was more likely to have previous sexual offense convictions. This offender engaged in multiple online identities. They modify their behavior and approach to fit the child's needs and to ensure success with the victim.

Some used and possessed child porn they had offense supporting cognition that focused on their own needs and viewed the victim as mature and capable of engaging in sexual contact but did not view the contact as a relationship. Some have small collections of child porn and tended not to have significant contact with other offenders online. These offenders adapted their identity and grooming to fit the victim's behavior and response. The contact occurred at the pace set by the victim. These offenders tended to be more security conscious and often had multiple electronic devices. ${ }^{196}$ This category is similar to cyber-sex only offenders identified by DeHart et al. ${ }^{193}$ This group engages in both online and offline sexual behavior. ${ }^{193}$ The hyper sexualized offender: These offenders were less inclined to meet the minor in person. Their discussion was highly sexualized and they spent little time or had little concern about the victim's life. They tended to have extensive child porn collections, some had extensive and extreme adult porn collections and to have significant contact with other offenders online. They tended to have previous convictions for child porn. They altered their identity and often used an avatar or picture of their genitals rather than of their face.

The contact was highly sexualized and moved quickly. Their offense supporting beliefs involved dehumanizing young people. They tended not to use the phone and did not personalize the conversation. Offline meetings were less common with this group. ${ }^{196}$ These offenders quickly introduced sexualized content and did not attempt to establish a relationship. In general, some studies have found that some offenders did not have to modify their behavior to fit the child's need's ${ }^{195}$ and none of the offenders in the study were adaptiveoffenders. The authors speculate that because of the significant number of children available online that the offender has no need to modify their approach or strategies to address noncompliant victims, which is supported by other researchers as well. ${ }^{194,196,205}$ Again, many online solicitation offenders may have engaged in undetected contact offenses. Victims may include children and adolescents. Contact driven solicitation offenders become "dual" or "mixed" offenders once they attempt or engage in physical contact with the victim.

Research supports that most solicitation offenders were contactdriven and therefore dual or mixed offenders. ${ }^{2,147,197}$ This impacts the research in that the fantasy-driven and contact-driven offenders may be counted as the same if the offender fails to disclose attempted or actual contact with a minor or the authorities or researchers failed to detect (via self-admission or polygraph) if the offender has attempted to or has met with a minor. Once a solicitation offender attempts or engages in offline contact with the victim, they should be considered dual offenders. Strategies and behaviors associated with grooming involves many different behaviors. The manipulation of minors often included encouraging the victim become actively involved in the sexual activities either online or offline and giving the appearance of freedom of choice. This may include asking the victims about their previous sexual experiences, graphically describing the types of sexual activities they would like to have with the child, and discussing with the child the inappropriate behavior of the relationship between the adult and the victim. ${ }^{206}$

\section{Those who engage in online grooming}

First, it should be noted that not all sex offenders or solicitation offenders (online/offline) engage in the grooming process. Some 
offenders move immediately into initiating sexual conversation, exchange of sexually explicit photos, and/or sexual behavior online or offline. These offenders quickly sexualize the conversation and may use coercion, pressure, threats or force to gain victim compliance or simply move on to the next victim. They utilize various strategies to engage in cyber-rape and online exploitation of the victim regardless of whether the sexual exploitation remains online or moves also to offline contact. ${ }^{197,236}$ This is similar to Webster et al., ${ }^{196}$ hypersexual offender. The online groomers structure the online environment to allow for maximum persuasion on minors. They engage the child to feel like they are an active part of the plot. This includes operating in multiple scenarios online with different potential victims at the same time. ${ }^{233,237}$ Anonymity allows for the offender to overcome personal and social barriers. ${ }^{233}$ The offender thoroughly studies the victim's environment and vulnerabilities and then develops strategies to involve the victim in the abuse. The in-person contact with the victim may occur once or on multiple occasions.

Situational factors (e.g., schedules of the victim's parents, level of autonomy of the victim on the Internet) aided the offender to cross barriers of social control and approaching minors. ${ }^{233}$ Online offenders (solicitation) tended to groom based on victim accessibility, opportunity, and the victim's perceived vulnerabilities, possibly victim attractiveness though not as likely. ${ }^{203}$ Most online offenders visited online chat rooms geared toward minors and most read the victim's profile. The online offender often chose victims who had sexual content in their profile, assessed the victim's perceived neediness or submissiveness, focused on victims whose profiles contained the victim's age, and when the victim had young-sounding usernames. ${ }^{203}$ One model identified how offenders actively involve minors in the process of online grooming and by doing so limits risk for detection. ${ }^{233}$ This model involved deception, corruption, and emotional involvement of the victim. By making the victim appear complicit in the grooming and subsquent sexual contact, the victim may come to accept the sexual behavior as acceptable or may experience guilt, shame or fear and blame themselves for getting into the situation.

Regardless, the victim may be less likely to tell anyone about the victimization and contact. Nearly $85 \%$ of victims reported (mostly to friends) the offender when asked to perform sexual behavior they did not want to engage in ${ }^{238}$ many of the victims also blocked further contact from the offender or terminated contact from the offender) after refusing unwanted sexual contact. ${ }^{238}$ Some offenders identify the affective needs of the victims in the early stages of contact (e.g., needy or submissive) as well as other vulnerabilities (e.g., family conflict, absenteeism from school). ${ }^{57,233}$ The next step of actively involving the victim in the grooming process decreased detection. If the victim was asked to engage in some sexual behavior they do not want to do they were more likely to report the sexual activity. ${ }^{238}$ Offenders engage in impression management, tending to maintain a positive image of themselves. ${ }^{170,196,233,239}$ This may help prevent detection by appearing to be a "normal" person at least as others may describe them.

Offenders tend to lack awareness of the inequity of the relationship between an adult and minor, equating the relationship as if it were an adult-adult relationship. ${ }^{233}$ The offender may use the victim's perception of being in love with the offender as justification for the romantic/abusive relationship. ${ }^{233}$ Offenders tended to believe that victims who took the initiative in the sexual interaction were therefore to blame for the sexual contact. Sexualized minors who took the initiative in the sexual interaction more quickly accepted direct sexual solicitations. ${ }^{233}$ Direct strategies offenders may use include offering money in exchange for sex or may offer a long- term relationship. ${ }^{233,240,241}$ Other strategies may encourage a greater affective involvement by the victim ${ }^{232,239,242}$ which serves to sustain the abusive relationship over time. Bribery may be used to offer free photo sessions to find work that is to expose their bodies to be selected in areas of fashion or movies. ${ }^{233}$ Most offenders have abused several victims. ${ }^{3,237}$ Victims include higher rates of females, followed by those who are gay minors or who have a poorly defined sexual identity, and

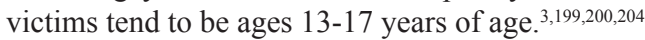

Offenders take advantage of the youth's vulnerabilities (e.g., need for attention and affection, depression, victimization). ${ }^{199,239,243,244}$ The offenders also engaged in contact with strangers over the Internet or using chat rooms. ${ }^{233,243,245}$ With extrafamilial child molesters, those who engaged in the no coercive pathway of sexual molestation (molested more victims, victim was not related or may have been a stranger, more time spent in planning the offense, and used less coercion) engaged in more deviant sexual fantasizing than those in the coercive pathway (mostly female victims, knew the victim, little planning of the offense, used coercion). ${ }^{222,246-248}$ Child molesters with both female and male victims and those with male victims experienced significantly more sexual fantasies prior to and after their first contact offense than those offenders with only female victims. ${ }^{222,249}$ Contact offenders mostly target adolescent girls (13-17), tend to be older than age 25 , and did not deceive the victim about their age or sexual wants. They also engaged in sexual contact with each victim more than once. ${ }^{200}$ This reflects Hebephilia (primary sexual attraction to early adolescents approximately ages 11-14) and Ephebophilia (primary sexual attraction to late aged adolescents approximately ages 15-19) not Pedophilia

Only a handful of contact offenders utilize physical force or coercion. Most offenders are not strangers, having engaged in contact online with the victim extensively prior to engaging in sexual contact. Most solicitation offenders (both fantasy-driven and contact-driven) either were honest about their age or indicated that they were younger, though none presented as being children or adolescents. ${ }^{2,195,199,205,206}$ One study found that about one-third of the offenders portrayed themselves as children. ${ }^{203}$ Despite the offender blaming the victim for initiating the sexual conversation, victims indicated that it was the offender who continued to bring up sexual topics. ${ }^{239}$ In that study, every victim described loving feelings towards the offender regardless of their emotional state or abuse history. Abuse was redefined as by the victim as being a loving relationship. The online communication was highly sexual, often involving flattery and compliments to facilitate sexual activity. ${ }^{195}$ initiated the conversation, acknowledged the victim's age, and then engaged in sexually explicit conversations. The offender took part in the sexual activity (e.g., taking explicit pictures of themselves, teaching masturbation, engaging in cybersex). The sexual content was discussed during the first conversation and the offender made their explicit sexual interests known. In one study $89 \%$ of the offenders introduced sexual contact in their first conversation with the decoy victim (the decoy victim was someone working for Perverted Justice). Most of the offenders attempted to engage in telephone contact with the victim and to organize meetings. , $^{3,24}$

\section{Contact offenders grooming strategies}

Contact offenders tended to groom and select a victim based on victim physical attractiveness, ease of access, and perceived vulnerabilities. ${ }^{4,209,221}$ Online offenders (solicitation) tended to groom based on victim accessibility, opportunity, and the victim's perceived vulnerabilities, possibly victim attractiveness though not as likely. ${ }^{203}$ Most online offenders visited online chat rooms geared toward minors and most read the victim's profile. ${ }^{203}$ The online offender often chose 
victims who had sexual content in their profile, assessed the victim's perceived neediness or submissiveness, focused on victims whose profiles contained the victim's age, and when the victim had youngsounding usernames. ${ }^{203}$ Offender's engage in sexual grooming to prepare the child for sexual contact. ${ }^{8}$ Craven et al., ${ }^{129}$ identified that the specific goals included "gaining access to the child, gaining the child's compliance, and maintaining the child's secrecy to avoid disclosure". The tactics used are meant to desensitize the children to the sexual requests as well as stimulate the children's sexual curiosity, lower the child's inhibitions, normalize the requested sexual behavior as depicted in the porn, as well as to normalize sexual relationships between adults and children. ${ }^{221,250,251}$

Offenders who engage in offline (contact) grooming strategies tend to use one or more of three types of grooming. ${ }^{209}$ These include:

i. Personal Grooming: strategies used to make contact with victims appear legitimate and gain power over children, building a rapport with the children be engaging in interests the children have and/or bribery with gifts;

ii. Family Grooming: preparing the children's parents by establishing a friendship with them, establish trust and gain cooperation in accessing the child; and

iii. Institutional Grooming: using own job or profession to access victims. Again, the term children includes adolescent victim as well. Usually offline aggressors are known to the child's family or acquaintances. ${ }^{132}$ The offender engages in strategies including selecting a vulnerable victim, gaining access to the victim, developing trust, and then desensitizing the victim to touch. ${ }^{128}$ Many of the grooming behaviors appear innocent in nature. ${ }^{129}$ Approximately $60 \%$ of the perpetrators are known to the child but are not family members; $30 \%$ are family members; $10 \%$ are stranger to the child; and approximately $23 \%$ of cases the perpetrator is under age 18 , and $90 \%$ of the perpetrators are male. ${ }^{130,136,137}$

Another investigator identified 4 steps of grooming a victim. ${ }^{3}$ These include:

i. Selection of a victim, based on attractiveness, ease of access, perceived vulnerabilities of the child; $4,209,252,253$

ii. Gaining access to the victim. The goal of isolating the child physically and emotionally from others (e.g., offering a ride, meeting with the victim alone, sneaking into the victim's home or bedroom, meeting after school; $;^{252,253}$

iii. Development of trust with the victim. This may include developing trust with the victim and/or the victim's family; ${ }^{4,209}$ and

iv. Gradually increasing physical contact in order to desensitize the victim to touch. ${ }^{254-257}$ When it came to identifying the above grooming behaviors, it was found that the above grooming strategies were difficult if not impossible to identify because the strategies used appear normal in interacting with others in general. $^{3}$

The above steps appear to have at least some degree of empirical support. Recognizing grooming behaviors is often difficult if not impossible. ${ }^{3,129}$ It should be noted that no specific order of grooming stages was found to be consistently supported by the literature. This suggests that each offender is unique to some degree in how they engage in the grooming process. However, specific grooming strategies were shared to some degree by all offenders. All interactions between the offender and victim were highly sexualized and the offenders were unique in their application of strategies and which of any stage of grooming they engaged in and in what order. ${ }^{195}$ This is consistent with other findings. ${ }^{166,258}$ Grooming is a term that is often confusing, and observers of grooming may not recognize the actual grooming behavior. ${ }^{195}$ Not all grooming behavior involves arrangements for meeting in person; some are only engaging in contact online. Grooming behavior may appear like any normal, appropriate behavior.

\section{Specific grooming strategies and behaviors}

\section{Introduction of sexual topics and compliments}

Sexual topics appear to be introduced early in the online grooming process. ${ }^{240,259,260}$ Offenders often used compliments to introduce sexual topics, playing with nonsexual and sexual conversation to establish a deeper rapport and to encourage the minor to engage in sexual behavior online. ${ }^{195}$ Sexual topics were often introduced as a joke or game. ${ }^{166,195,205}$ Complements often focused on sexual physical appearance and nonsexual appearance, then personal compliments. ${ }^{232}$ Seeking information about the child's sexual interests and experiences is also useful in establishing compliance with sexual requests. ${ }^{194}$ Secrecy, establishing a sense of mutuality, and a sense of a relationship also help to ensure the child's compliance. ${ }^{261}$ The offender may send the victim sexually explicit pictures or videos of themselves or commercial porn to desensitize the victim to the sexual content as well as to normalize the depicted sexual behavior. ${ }^{194,195,203,262,263}$ Adding compliments and flattery to the conversation reassures the victim's compliance and decreases risk of disclosure.

\section{Pressure, coercion, \& threats}

"Boundary-pushing" is a term used to describe the process of pressuring the victim to comply with sexual directives and overcome resistance. ${ }^{166,195,205}$ At times the offender may have minimal interest in the victim's personal life and may simply progress to using more direct and blunt directives. ${ }^{195}$ The offender may utilize more direct and aggressive language to direct the victim into compliance. The offender may also persistent and use non compromising pressure to coerce victim cooperation and may then become more verbally gentle to retain victim cooperation. ${ }^{194,206}$ Threats, intimidation, blackmail, gifts, bribes, seduction and competition are some of the strategies used by the offender. ${ }^{261,264}$ The sexual behavior of the child is often recorded by the offender for sexual gratification and may also be used to blackmail and threaten the child into continued submission and compliance and secrecy. ${ }^{2,194,243,262}$

\section{Actively involve the victim}

Many offenders actively involve minors in the process of online grooming by using sexualized language and conversations. ${ }^{194,195,242}$ Emotional involvement of the victim helps to make the victim appear complicit in the grooming and subsquent sexual contact thereby the victim may come to accept the sexual behavior as acceptable or may experience guilt, shame or fear and blame themselves for getting into the situation. The sexualized conversation and personal sexual disclosures made by the offender help normalize the sexual focus. Regardless, by involving the victim and early desensitizing the victim to the sexual content, the victim may be less likely to report the contact. Sharing sexually explicit pictures, masturbatory acts, and explicit sexual talk via web cam are tactics used to desensitize the child and encourage compliance with sexual demands. ${ }^{2,194,203,206,262}$ The sexual behavior of the child is recorded by the offender for sexual gratification and may also be used to blackmail and threaten the child into continued submission and compliance and secrecy., 2,194,203,206,262 
Some offenders may use more direct implicit and explicit sexually suggestive and coercive language to stimulate the child's sexual curiosity and compliance. ${ }^{221}$

\section{Relationship building}

Contact driven offenders are more likely to use positive and negative words, with first person pronoun to show trust to the victim target, thereby encouraging the victim to reciprocate. ${ }^{265,266}$ This technique is effective because it is the same used in healthy relationships involving self-disclosure. Some offenders spent time getting to know the victim and engaging in relationship-building. Others were very direct and blunt, immediately introducing sexual contact. ${ }^{240}$ These resemble the strategies of rapists ("blitz", "con", and "surprise") ${ }^{267}$ in order to gain victim compliance. The offender also employs at least some relationship-building to maintain contact with the child over time. ${ }^{259}$ The research is mixed to the degree of time (e.g., minutes, days, months) that offenders spent in relationship-building or maintain ongoing contact with the victim as most offenders engaged in contact with multiple victims simultaneously., $440,258-260$

Specific grooming techniques included flattery, compliments, making the victim feel special, sexualize the conversation to introduce sexual topics, erratic or nasty temperament, and grooming individuals in the victim's life to gain sexual compliance. ${ }^{258,259}$ In addition, the offender may use threats, intimidation and blackmail. The use of bribes, gifts, seduction, and competition are often used as well. ${ }^{261,264}$ In addition, the offender may use threats, intimidation and blackmail. The use of bribes, gifts, seduction, and competition are often used as well. ${ }^{261,264}$ Victims were then encouraged to expose themselves online. The indirect offender would be persistent, begging and desperate, gentle pressuring through displays of disappointment, reminding the victim they promised to engage in the requested behavior. Offenders using the direct approach used threats, blackmail, insults, peer pressure.

Both approaches utilized pornography to desensitize the victim to sexual topics, lower their resistance, and gain their compliance. ${ }^{205,206,240,268}$ These are similar strategies used by contact offenders as well, not just those online. ${ }^{258}$ The establishment of a loving relationship is often used by the offender. ${ }^{239}$ In one study, all of the victims described loving feelings towards the offender regardless of their emotional state or abuse history. Abuse was redefined by the victim as being a loving relationship. Compliments and flattery were also used in addition to making the child feel special to agree to engage in the sexual requests. In addition, the offender may use threats, intimidation, and blackmail. The use of bribes, gifts, seduction, and competition are often used as well. ${ }^{261,264}$

\section{Encouraging or involving the victim in sexual contact online}

Some offenders introduce sexual content immediately or very early in the conversation and may share sexual photos or engage in sexual activity (Exhibitionism) via their webcam to get the victim to reciprocate. ${ }^{2,195,266}$ Online only offenders (fantasy-only) are likely to teach the victims about sexual behaviors or use exhibitionism to get the victim to reciprocate. ${ }^{2}$ Contact offenders used the Internet to groom their victim by sending both child and adult porn to the victim. ${ }^{138}$ The introduction of sexual themes in conversation as well as showing porn help desensitize the victim to sexual themes and to encourage the child to engage in the requested sexual activity. ${ }^{261,264}$

\section{Discussion of choice media}

Another strategy used with online offenders involves often beginning with a discussion of the choice media (e.g., social networks, chats, text messages) and elements of gaining access to minors. They often targeted several potential victims at the same time. ${ }^{260}$ They searched for vulnerable or sexually curious targets and adapted to the needs of the victim.

\section{Deceiving about offender's age}

Most of the predators pretended to be considerably younger across a number of areas (e.g., name, physical appearance, interests). ${ }^{260}$ Other studies found that the men did not lie about their age. ${ }^{200}$ It was found that offenders with victims 14-18 years of age did not include deceit, violence, or intimidation. ${ }^{238}$ These inconsistencies may be due to the specific populations studied or may simply represent the diversity of strategies used by offenders.

\section{Offender self-disclosures}

Online only (fantasy-only) child offenders tended to make far less self-disclosure to avoid detection as well as they had no intent to meet the child in person. ${ }^{266}$ Contact offenders tended to share more selfdisclosures with the victim to increase sharing and trust. ${ }^{266,269}$

\section{Networking with other child predators/liked minded people}

Contact offenders tended to network and communicate with others who shared similar deviant interests. This helped serve to encourage and support the offender's deviant fantasies, beliefs and behaviors.

\section{Distorted cognitions of online offenders}

In general, sexual offenders tend to share common distorted thinking to justify their use of child porn as well as to justify engaging in sexual contact with children and adolescents. The degree to which the offender shares any of the following examples is unique to the individual offender. Minimization of harm to the child included believing:

a. There was no direct contact with the child. ${ }^{169}$

b. The children depicted in the porn did not display signs of resistance or harm or may have appeared to enjoy the sexual contact. The child is not believed to be harmed by the sexual contact. ${ }^{151,170,225,270,271}$

c. The belief that there was no harm to the child for viewing child porn or engaging in sex with children or adolescents. ${ }^{225,270}$

d. Viewing themselves as being unable to control their urges or behaviors, that they are unable to stop themselves and this has been referred to in the literature as external locus of control. Offenders exhibited characteristics of impulse control or feelings of addiction to the Internet and therefore believing that they are out-of-control. ${ }^{140,149,272-274}$

e. Viewing children as sexual beings or sexual objects. Children are viewed as wanting to engage in sex and that they enjoy sex. ${ }^{91,225,247,275}$

f. Some offenders may blame the victim for engaging in the sexual contact and debase the victim for doing so (e.g., blaming the victim for initiating or continuing in the grooming process, highlight the victim's willingness to engage in sexual behavior [viewed by the offender as sexual debauchery], and sexualizing the victim). ${ }^{3,233,239}$

g. Having a sense of entitlement to engage children or adolescents in sexual activities. ${ }^{270}$ 
h. Viewing the world as being dangerous or a threatening place at one extreme and the world as a limiting and unsatisfying place at the other extreme. Emotional problems and attachment deficits contribute to this. . $^{39,270,276,277}$

i. The offender believing that they are a collector and that the material provides sexual satisfaction and provides a depiction and reinforcement of a sexual fantasy or preference. $^{4,20,134,172,225,278,230}$

\section{Risk factors}

It should be noted that solicitor child molesters are equally as dangerous as contact offenders. ${ }^{204}$ Those who solicit and those who engage in contact offenses utilized similar grooming and offense tactics. The online solicitor engages in sexually abusive and threatening behavior, thereby victimizing the online victim. ${ }^{197}$ In addition, most child porn users and fantasy-driven solicitators appear to engage in actual sexual contact with the victims, again per selfreport of undetected offenses. Those with previous criminal histories for child porn present with higher risk for contact sexual offenses. ${ }^{134}$ The ability to groom suggests that the offender is comfortable with communicating with their victim and makes crossover to contact offenses highly likely, perhaps even early in the interaction with the victim. $^{2,129,134,169}$ The research further indicates that the production of images tends to be hands-on recording with the offender actively involved in the sexual activity. ${ }^{134,217}$ offenders tend to use grooming techniques to have their victim engage in sexual activity via webcam. ${ }^{169}$ There does not appear to be any difference between online solicitation offenders and contact offenders in terms of dangerousness. ${ }^{204}$

Solicitation offenders tended to range in age from 19-64, suggesting that older range of over 50 may not actually age-out of offending as once suspected. ${ }^{3}$ Offenders tended to target victims within a close geographical proximity, ${ }^{3}$ which suggests their intent to meet with the victim in person and most made their sexual intentions clear immediately (approximately within first 35 minutes). ${ }^{3,163,206}$ The majority of offenders and victims exchanged pictures the first day. ${ }^{3}$ This may help desensitize the victim to sexual material and activity. Most offenders appear to be contact driven versus fantasy driven, ${ }^{3}$ with over $80 \%$ initiating telephone and email contact with the victim. The online offender often chose victims who had sexual content in their profile, assessed the victim's perceived neediness or submissiveness, focused on victims whose profiles contained the victim's age, and when the victim had young-sounding usernames. This suggests predatory behavior and strategic capabilities which are often underestimated with the solicitation offender. Many offenders are in contact with multiple victims at the same tim. ${ }^{3}$

Much of the grooming occurred to allow for contact within 3 days ${ }^{3,208}$ whereas others take their time to develop the relationship. ${ }^{128,209}$ This poses a concern that perhaps the majority of solicitation offenders are contact-driven versus fantasy-driven. On the other hand, perhaps the fantasy-driven offender more quickly moves to contact with the victim to address strengthened power and sexual motivations, which would make sense from a conditioning standpoint. Internet behavior involving sexual grooming and production of child porn represent an escalation of viewing or possessing child porn because the offender is now communicating their sexual interests to others. ${ }^{2,134,279,280}$ This may suggest comfortability with the deviant sexual interest as well as a comfortability with engaging in contact offenses. Child porn offenders with smaller collections of child porn (e.g., 50) represented the highest risk group for engaging in contact offenses. ${ }^{134,281}$ This is in opposition to McCarthy who found that the dual offenders had the largest child porn collection. Extreme child porn images are rarely found in the child porn offender's collection, likely because the offender does not justify injuring the child. ${ }^{282}$

Some have suggested that a porn collection involving child porn is a strong indicator of Pedophilia. ${ }^{177}$ Offenders with child porn collections were more likely to demonstrate a pattern of sexual interest in children more so than contact offenders. ${ }^{177}$ However, the presence of child porn cannot be the sole evidence to support a sexual preference for children. Some offenders have a sexual interest in children but not exclusively to children, often involving adults as well. Some of these offenders who have a stronger sexual preference for children versus adults are likely to demonstrate difficulties in their sexual relationships with adults. Some may engage in sexual contact with adults solely to access children. ${ }^{4}$ For others, they may collect child porn out of curiosity or other nonsexual needs. Sex offenders who reinforce their sexually deviant and nonsexual violent motivations through repeated viewing of deviant porn and child porn are at higher risk for sexual reoffense and contact offenses. This is supported by general learning theory and the concept of habituation and is supported in the literature for sexual offense behavior. ${ }^{10,283-288}$ In fact, masturbating to erotica (anything that a person finds sexually arousing) that is in any way related to a deviant sexual attraction or sexual offense behavior should be banned by use and possession by the offender.

The cognitive distortions (e.g., rationalizations and excuses) offenders use to maintain their deviant sexual arousal and deviant sexual behavior help maintain the problem and may serve as permission giving. ${ }^{225}$ A small number of Internet only offenders downloaded more extreme pictures. ${ }^{148}$ This may indicate increased impulsivity, more extreme and deviant thoughts, and may represent a progression toward contact offenses, though more research is needed. Sexual preferences and sexual preoccupation appear to be underestimated in samples of detected offenders. ${ }^{168}$ This is likely due to poor assessment and diagnostic procedures. Perhaps the limited information about the offender's true sexual preference and paraphilias prevent accurate and appropriate diagnoses from being given. Some mental health and treatment professionals fail to provide all diagnoses the offender presents with and therefore an accurate picture is not available as to the breadth of the offender's pathologies. Of course, lack of polygraph for assessment and treatment may result in having to rely on the offender's words about their sexual preference and the degree of their sexual and psychological problems. Most sexual offenses against children are vastly undetected and unreported. ${ }^{2013}$ This is likely due to the reliance of offender denials of having any or significantly more contact victims.

Researchers and treatment professionals need to assess for all mental health diagnoses as well as utilize polygraph and sexual arousal/attraction testing protocol (e.g., plethysmography, visual reaction time). The research clearly indicates that most child porn only offenders indeed have multiple contact victims and that most contact offenders have far more victims than detected. It has been proffered that use of child porn may help some control sexual deviance while for others facilitates acting on preexisting fantasies and urges. ${ }^{179}$ However, viewing deviant material may stimulate existing fantasies and lower inhibition leading to contact offenses. ${ }^{179}$ Repeated viewing of child porn and/or contact with other offenders may weaken resolve 
leading to contact offense. Even finding child porn accidentally while searching for regular porn impacts potential for continued child porn use and perhaps to contact offenses. It is not recommended that anyone that has a sexual interest in children or adolescents, or has engaged in contact behavior with a minor, continue to use child or adolescent porn.

The argument that it may help quell deviant desires goes against logic, research, and learning theory. Practice makes perfect, continued use of any child porn (including adolescent porn) strengthens deviant arousal and deviant thinking. The longer the sex offender spends in sex offender specific treatment, the more deviant fantasies they report. ${ }^{222}$ The reason for this is unclear. Perhaps the offender becomes more aware of their fantasies while in treatment and therefore more openly acknowledges them; maybe the offender comes to believe that they are expected to have the deviant fantasies because treatment talks about and focusses on them; or maybe the fantasies are not likely to fade away.

\section{Investigative applications}

i. Never underestimate the significance of nuisance sex offenses as these offenses often are part of an offenders larger deviant scheme. ${ }^{155}$

ii. Pay attention to any similarities between the nuisance offenses and actual sexual offense behavior. ${ }^{4}$

iii. Pay attention to probation violations and any failed court orders including the use of alcohol, failing to report as directall indicating a willingness to ignore rules and to engage in potentially risky behavior. Offenders with a prior history of violation of conditional release were more likely to offend, violently and nonviolently. ${ }^{175}$

iv. Grooming strategies used by online offenders and offline (contact) offenders are very similar. These are similar strategies used by contact offenders as well, not just those online. ${ }^{258}$

v. Offenders may spend more time establishing a relationship with male victims prior to meeting. ${ }^{194,262}$

vi. Many of the offenders may not have any criminal history or no criminal sexual offense history. This does not make the offender any less dangerous, it simply means they likely have never been arrested or detected in the past.

vii. Of those offenders who had no prior sex offense convictions but admitted having undetected contact victims, they had the most victims. ${ }^{135}$

viii. Many of the child porn offenders with the most contact offenses went undetected at least in part to their not having a criminal history and skills at grooming. ${ }^{155}$

ix. For child porn cases, always investigate for contact offenses. Look into any contact they may have with children/minors, any position of power/authority they may have had with minors. ${ }^{155}$ This should also include investigating the neighborhood they live in (e.g., playgrounds, churches, pools, schools) as the offender may hang around those areas watching children or engaging the children in activities. Child porn offenders with no prior sex offense convictions admitted having the most undetected victims, and their ability to remain undetected for so long requires special attention to investigate the offender's life. ${ }^{135}$

x. Child porn only offenders are more likely to confess to police and admit the child porn possession. They do this to lessen the chance that law enforcement would further investigate and detect that they have contact victims. ${ }^{169}$

xi. A high percentage of children sexually abused likely never report the sexual contact or may not do so until they are much older, reducing the likelihood of prosecution due to the time lapse. ${ }^{290}$

xii. Always ask victims if the offender took pictures of them. If so, find the pictures and what was used to take the pictures or videos (cell phone, camera). The sexual behavior of the child is almost always recorded by the offender for sexual gratification and may also be used to blackmail and threaten the child into continued submission and compliance and secrecy. ${ }^{2,194,205,243,262}$ In addition, the offender may use threats, intimidation, blackmail, bribes, gifts, seduction, and competition to gain victim compliance and secrecy. ${ }^{261,264}$

xiii. The offender may use threats, intimidation, blackmail, bribes, gifts, seduction, and competition to gain victim compliance and secrecy. ${ }^{261,264}$

xiv. Child porn offenders are likely to confess to possessing child porn; this is often misleading because by accepting a plea agreement, law enforcement is not likely to investigate for the presence of contact victims. ${ }^{4,135}$ This is especially true when the offender is very anxious to plead guilty.

xv. Use of polygraphy during the investigative process yields more admissions of contact victims. ${ }^{123,133,216,291,292}$

xvi. It is estimated that likely $62 \%$ of child porn only cases would turn out to be contact offenses if polygraph is used. ${ }^{135}$ Again, $40-85 \%$ of child porn only offenders self- reported having undetected contact victims. ${ }^{123,173,174}$

xvii. Offenders demonstrate strategic capabilities in their assessment of potential victim, the specific grooming process, and their ability to coerce victim compliance and secrecy. This suggests predatory behavior and strategic capabilities which are often underestimated with the solicitation offender.

xviii. Most solicitation offenders are likely contact-driven versus fantasy-driven given that most fantasy-driven offenders engage in contact offenses. Some take time to establish and develop a relationship with the victim whereas others move quickly to establish offline contact with victims, but most all eventually engage in contact offending. ${ }^{3,128,208,209}$

xix. Listen careful to how the offender justifies their deviant behavior (e.g., use of child porn, engaging with children whether sexual or nonsexual, how they defend any sexual contact with children). This helps to understand the offender's rationalizations and justifications for engaging in the offense behavior.

xx. Many offenders are in contact with multiple victims at the same time. $^{3}$

xxi. View any porn collection as a probable Practice and Premeditation process. Practice because the offender uses the porn to strengthen deviant sexual and/or aggressive fantasies and even rehearsing how to re-enact the fantasy in real-life. Premeditation because of the planning and fantasizing that occurs prior to initiating contact with the victim, especially when the themes or behaviors depicted in the porn matches the offenders' offense behavior. In addition, pornography is often used by the offender to desensitize children and adolescents before sexually abusing them. 
xxii. For forensic mental health I recommend that any sex offense warrants a diagnosis of a Paraphilia.

While several Paraphilias are provided in DSM-5, perhaps the most important is Paraphilia-Unspecified. To pair sex, sexual behavior, sexual arousal with love, respect, excitement is understandable. To engage in a sexual offense, regardless of age of victim, the opposite must be true. To be able to maintain sexual arousal with a nonconsenting partner, an unconscious partner, an animal, or any other deviant arousal, would be nearly impossible without some degree of acceptance for use of force, coercion, or to maintain sexual arousal and/or complete a sexual act despite victim resistance, pain, suffering, humiliation, young age, etc. The offender must have some degree of acceptance for engaging in deviant sexual behavior. When using Paraphilia-Unspecified, put into parenthesis the adjective that best describes the offender's offense behavior (which in turn gives a picture of the offender's thoughts and cognitive distortions), for example, "forced sex", "rape", "sex with an unconscious person".

\section{Limitations of the available research}

i. One of the most difficult and frustrating issue that interferes with the accuracy of research is that limitations are always present. In the above literature review, several limitations are present.

ii. The data is based only on child porn users, contact offenders, and dual offenders who have been identified because of arrest, prosecution, and for some, involvement in sex offender specific treatment. Therefore the generalizability of the findings are limited only to those offenders who have been identified and apprehended.

iii. Much of the data was based on the self-report of the offender. This raises serious questions about the veracity of the offender's claim. Some child porn offenders may deny that they have engaged in contact sexual offenses with children or adults despite having done so. The opposite is also true. Some offenders may admit to behaviors that they have not actually engaged in and may do so for a variety of reasons (e.g., impression management (e.g., to appear cooperative in treatment or with prosecution); psychological problems (e.g., wanting to appear more self-assured, powerful, or dangerous than they really are). Without polygraph, the offender's claims are just that- claims of someone who has engaged in sexually deviant and/or violent behavior who is not likely to be totally honest.

iv. The follow-up period is often less than 3 years. This presents a significant problem because the offender remains at risk for violent and/or sexual reoffense for life. In addition, most recidivism studies rely on the offender' self-report. Even if a criminal history check was made and no prior offense was detected, that may mean

a. They have not yet been caught; or

b. They did not yet reoffend or progress to contact offenses. Most of the child porn and contact offenders, like any other offender, have typically offended for years prior to being caught. It may be another 5-10 years before they offend or before they are again caught.

v. Methodological problems were apparent in many of the studies.197 Several of the studies have small sample sizes, making it difficult to generalize the findings. In fact, several studies were limited to 5 offenders and others far too few to allow adequate comparisons between offender typologies. Many of the studies, though well intentioned, failed to adequately define the population studied, that is, the specific type of sex offender they were studying. Many grouped all child sexual abusers into one category, failing to differentiate the child porn only offenders from online solicitation offenders (fantasy-only) or from those who engaged in contact offenses (contact- driven) as well as failed to differentiate the situational and preferential offenders. The literature is rich with differences in motivation and cognitive distortions between these groups. It is imperative to have clear working definitions.

vi. Several studies referred to groomers to include those who did not engage in the development of a relationship with the victim, which is in fact the process of grooming. Some offenders move immediately into soliciting sexual contact online or offline thereby skipping the grooming process altogether.193,231,232 The process of grooming and the separate process of soliciation for sexual activity need to be clearly separated and defined. The grooming of the victim and the solicitation of sexual activity from the victim occur faster online than offline and can be difficult or confusing to separate. ${ }^{293}$

vii. Some of the research on online predators often involves victims who were undercover investigators versus actual victims.205,206,208,233 This presents some degree of difficulty in determining how a real victim may respond. Studies have found, however, that it is the groomer (offender), not the victim or decoy, that leads the conversation.3,197,294 However, because decoy victims do not engage in online sexual behavior (e.g., masturbation, exchanging naked photos) they may turn the offender away.193,234 If the offender believed that the victim was of legal age, they tended to proceed with sexual contact regardless of whether the victim was a decoy. This suggests that decoys or actual victims likely react in similar ways but have limitations of what they can and cannot do. Overall, reliable data is likely to be obtained.

viii. Understand the difference between child molester, pedophile, hebephilic, and ephebophilia. A pedophile has a primary sexual attraction to prepubescent children (typically 12 and under). A hebephilic has a primary sexual attraction to early adolescents (approximately ages 11-14). A ephebophilic has a primary sexual attraction to late aged adolescents (approximately ages 15-19). Any of these three types of sexual abusers may engage in sexual contact with adults for primarily nonsexual needs, such as gaining access to children or for impression management (to appear "normal") or because there are situational offenders. A child molester engages in sexual contact with children for nonsexual needs, and likely has no sexual attraction to children (a situational offender). They are primarily sexually attracted to adults and prefer to engage in sex with adults but will substitute a child sex partner when circumstances or needs arise.

ix. Some of the research included both fantasy-driven and contact-driven offenders therefore confusing the two different offending groups (e.g., counting both groups as one) with little differentiation of how the two distinct groups offended or differed from each other in the research summary.

\section{Summary}

The shared factors and background of any of the sex offenders are often more significant than the differences. Online only offenders appear to experience more difficulty in their ability to engage in and 
sustain relationships, which is one of the main reasons why they offend online. However, isolation increases with continued deviant porn use and real life contacts begin to become less frequent. ${ }^{296}$ Offenders that contact other likeminded individuals online receive support for their deviant fantasies and deviant behavior and are likely to become more comfortable and brazen in progressing to online and offline contact with minors. The same could be said for offenders with adult victims. Psychological difficulties mostly included mental health diagnoses of mood disorders, anxiety disorders (mostly Social Anxiety), Substance Use, and Antisocial Personality Disorder. ${ }^{297,298}$ Low self-esteem, social anxiety, difficulty establishing or maintaining adult relationships, anger, and childhood maltreatment were common among most all of the offender groups the contact offender having more relationship skills.

However, mostly the differences were minimal One of the main difficulties in claiming that online offenders or child porn only offenders are less dangerous than contact offenders is that any of the offenders can chose to behave in more aggressive and more direct contact at any time, based on the two most difficult factors to assess, which are opportunity and circumstance on one end and personal choice on the other. ${ }^{299,300}$ Maintaining and strengthening deviant arousal through continued use of child and other deviant porn increases the likelihood of offender crossover. In addition, erotica, the specific things a person finds sexually arousing, can include items that are deviant in nature (e.g., child and deviant porn, children's clothing, non-nude photos of children, bondage items, etc) and when paired with repeated use these deviant items now support the likelihood that the offender will choose to act on their fantasies. This is even more supported when the offender masturbates to the deviant erotica and even more so when the deviant erotica is related behaviorally to any offense behavior. ${ }^{301,302}$ It is difficult to determine and identify which fantasy-only offenders will crossover and become contact offenders.

The most difficult factor is in determining when the offender has actually crossed-over to become the contact offender until they are actually arrested, which may be years before detection. Asking offenders who have been arrested and are in sex offender treatment whether or not they have contact offenses/victims they have not been yet caught for is important but presents with the major limitation of whether the offender is being honest and forthcoming when questioned..$^{303-308}$ Without use of polygraph, we only have the offender's word, which is not generally reliable. The offender may deny having contact offenses to avoid possible criminal prosecution or may acknowledge having contact offenses in order to present themselves as engaged in the sex offender treatment program. ${ }^{123}$ In addition, the use of sex offender specific testing (e.g., Plethymography, visual reaction time) as well as consistent use of polygraphy is needed consistently in the assessment and treatment of sexual offenders. It is difficult to determine in what order the use of child porn or the use of the Internet to chat with or engage in offline contact with victims occurred. ${ }^{193,309-313}$

Some offenders may well have been engaging in contact sex offending with minors prior to utilizing child porn or the Internet. Other may have begun to use the Internet to find child porn and then engaged in chat leading to sexual activity. Regardless, the Internet has become an effective tool for the sexual predator. In conclusion, we know a lot about sexual offenders. The literature provides a significant amount of information about the background and motivations of sexual offenders. ${ }^{314-317}$ The research suggests that most sex offenders share similar backgrounds, similar life experiences, similar psychological problems, and similar nonsexual motivations. It is important to always identify the offender's specific motivations, many of which are nonsexual in nature. The offender's choice of how to engage in offense behavior is always somewhat unique despite sharing similar rationale. There are significant similarities between the child sexual offender, child porn user, and adult rapists. In addition, research supports that many of the child porn only offenders admit to or are later found to have contact victims, and the undetected contact sexual offender tends to have the most victims per person.

\section{Acknowledgments}

None.

\section{Conflicts of interest}

The author declares that there are no conflicts of interest.

\section{References}

1. Groth AN. Men who rape. Plenum Press: New York. 1979.

2. Briggs P, Simon WT, Simonsen S. An exploratory study of Internet initiated sexual offenses and the chat room sex offender: Has the Internet enabled a new typology of sex offender? Sexual Abuse. 2011;23(1):72-91.

3. Winters GM, Jeglic EL. Stages of grooming: Recognizing potentially predatory behaviors of child molesters. Deviant Behavior. 2017;38(6):724-733.

4. Lanning KV. Child molesters: A behavioral analysis. For Professionals Investigating the Sexual Exploitation of Children. National Center for Missing \& Exploited Children. Office of Juvenile Justice and Delinquency Prevention. 2010.

5. Hazelwood RR, Lanning KV. Collateral materials in sexual crimes. In: Hazelwood RR, Burgess AW, editors. Practical Aspects of Rape Investigation: A Multidisciplinary Approach, 4th ed. Boca Raton, Florida: CRC Press, Inc. 1995.

6. Hazelwood RR, Warren JL. The relevance of fantasy in serial sexual crime investigations. In: Hazelwood RR, Burgess AW, editors. Practical aspects of rape investigation: A multidisciplinary approach, 4th ed. Boca Rotan, FL: CRC Press. 2009;55-64 p.

7. Johnson SA. Erotica and the sexual offender: The importance of restricting sex offenders from using or possessing erotica and pornography. Forensic Research \& Criminology International Journal. 2018;6(2):00186.

8. Finkelhor D. Child Sexual Abuse: New Theory and Research. New York: Free Press. 1984;77(2):477-481.

9. Kuhle LF, Neutze J, Amelung D, et al. Treatment-change in child pornography offending in pedophiles and hebephiles in the Prevention Project Dunkelfeld. Paper presented at the conference of the International Association for the Treatment of Sexual Offenders, Berlin, Germany. 2012.

10. Helmus L, Hanson RK, Babchishin KM, et al. Attitudes supportive of sexual offending predict recidivism: A meta-analysis. Trauma, Violence \& Abuse. 2013;14(1):34-53.

11. Seto MC. Internet sex offenders. Washington DC: American Psychological Association. 2013.

12. Johnson SA. Understanding the violent personality: antisocial personality disorder, psychopathy, \& sociopathy explored. Forensic Research Criminology International Journal. 2019;7(2):76-88. 
13. Lanning KV. Cyber "pedophiles": A behavioral perspective. In: Hazelwood RR, Burgess AW, editors. Practical aspects of rape investigation: a multidisciplinary approach, 4th ed. Boca Raton, FL: CRC Press. 2009;381-407 p.

14. Burton DL. Male adolescents: Sexual victimization and subsequent sexual abuse. Child and Adolescent Social Work Journal. 2003;20(4):277-296.

15. Brown J, Cohen P, Chen H, et al. Sexual trajectories of abused and neglected youths. Journal of Developmental and Behavioral Pediatrics. 2004;25(2):77-82.

16. Cortoni F, Marshall WL. Sex as a coping strategy and its relationship to juvenile sexual history and intimacy in sexual offenders. Sexual Abuse: A Journal of Research and Treatment. 2001;13(1):27-43.

17. Smallbone SW, McCabe BA. Childhood attachment, childhood sexual abuse, and onset of masturbation among adult sexual offenders. Sexual Abuse: A Journal of Research and Treatment. 2003;15(1):1-9.

18. Putnam FW. Ten-year research update review: Child sexual abuse. Journal of the American Academy of Child and Adolescent Psychiatry. 2003;42(3):269-278.

19. Rind B, Tromovitch P. A meta-analytic review of findings from national samples on psychological correlates of child sexual abuse. Journal of Sex Research. 1997;34(3):237-255.

20. Seto MC, Lalumière ML. What is so special about male adolescent sexual offending? A review and test of explanations through meta-analysis. Psychological Bulletin. 2010;136(4):526-575.

21. Jespersen AF, Lalumière ML, Seto MC. Sexual abuse history among adult sex offenders and non-sex offenders: A meta-analysis. Child Abuse \& Neglect. 2009;33(3):179-192.

22. Groth AN, Burgess W. Sexual dysfunction during rape. New England Journal of Medicine. 1977;297(14):764-766.

23. Hazelwood RR, Roboussin R, Warren JI. Correlates of Increased Aggression and the Relationship of Offender Pleasure to Victim Resistance. Journal of Interpersonal Violence. 1989;4(1):65-78.

24. Phillips EA, Rajender A, Douglas T, et al. Sex offenders seeking treatment for sexual dysfunction-Ethics, medicine, and the law. The Journal of Sexual Medicine. 2015;12(7):1591-1600.

25. Bownes IT, O Gorman EC. Assailants Sexual Dysfunction during Rape Reported by Their Victims. Medicine, Science and the Law. 1991;31(4):322-328.

26. Carvalho J, Quinta GA, Nobre PJ. Original research: The sexual functioning profile of A nonforensic sample of individuals reporting sexual aggression against women. The Journal of Sexual Medicine. 2013;1(10):1744-1754.

27. Boillat C, Deuring G, Pfluger MO, et al. Neuroticism in child sex offenders and its association with sexual dysfunctions, cognitive distortions, and psychological complaints. International Journal of law and Psychiatry. 2017;54:83-89.

28. Kaplan HS. The effects of illness on sexuality. In: Kaplan HS, editor. The new sex therapy: Active treatment of sexual dysfunctions. New York: Times Books. 1974;75-85 p.

29. Masters WJ, Johnson VE. Human sexual response. Boston: Little, Brown. 1966.

30. Bender J. Sexuality, chronic diseases and physical limitations: can sexuality be rehabilitated? Tijdschrift voor Seksuologie. 2003;27(4):169177.

31. Levine SB, Risen CB, Althof SE. Handbook of clinical sexuality for mental health professionals. New York: Brunner: Routledge. 2003.
32. Verschuren JEA, Enzlin P, Dijkstra PU, et al. Chronic Disease and Sexuality: A Generic Conceptual Framework. Journal of Sex Research. 2010;47(2):153-170.

33. Aromäki AS, Lindman RE, Eriksson CJP. Testosterone, sexuality and antisocial personality in rapists and child molesters: a pilot study. Psychiatry Research. 2002;110(3):239-247.

34. Dabbs JM, Morris R. Testosterone, social class, and antisocial behavior in a sample of 4,462 men. Psychological Science. 1990;1(3):209-211.

35. Daitzman R, Zuckerman M. Disinhibitory sensation seeking, personality and gonadal hormones. Personality and Individual Differences. 1980;1(2):103-110.

36. Berlin FS. Sex offenders: A biomedical perspective and a status report on biomedical treatment. In: Greer JE, Stuart IA, editors. The Sexual Aggressor: Current Perspectives on Treatment. Van Nostrand Reinhold Company. New York. 1983.

37. Berlin FS, Coyle GS. Sexual deviation syndromes. The Johns Hopkins Medical Journal. 1981;149(3):119-125.

38. Hall GCN, Hirschman R. Toward a theory of sexual aggression: A quadripartite model. $J$ of Consulting and Clinical Psychology. 1991;59(5):662-669.

39. Polaschek DLL, Ward T. The implicit theories of potential rapists: What our questionnaires tell us. Aggression and Violent Behavior. 2002;7(4):385-406.

40. Porter S, Newman E, Tansey L, et al. Sex offending and social anxiety: A systematic review. Aggression and Violent Behavior. 2015;24:42-60.

41. Kafka MP, Hennen J. A DSM-IV Axis I comorbidity study of males $(n=120)$ with paraphilias and paraphilia-related disorders. Sexual Abuse. 2002;14(4):349-366.

42. Kafka M, Prentky R. Attention-deficit/hyperactivity disorder in males with paraphilia-related disorders: A comorbidity study. The Journal of Clinical Psychiatry. 1998;59(7):388-96.

43. McElroy SL, Soutullo CA, Taylor P Jr, et al. Psychiatric features of 36 men convicted of sexual offenses. The Journal of Clinical Psychiatry. 1999;60(6):414-420.

44. Raymond NC, Coleman E, Ohlerking F, et al. Psychiatric comorbidity in pedophilic sex offenders. The American Journal of Psychiatry. 1999;156(5):786-788.

45. Alish Y, Birger M, Manor N, et al. Schizophrenia sex offenders: A clinical and epidemiological comparison study. International Journal of Law and Psychiatry. 2007;30(6):459-466.

46. Carlstedt A, Innala S, Brimse A, et al. Mental disorders and DSM-IV paedophilia in 185 subjects convicted of sexual child abuse. Nordic Journal of Psychiatry Volume. 2005;59(6):534-537.

47. Dunsieth NW Jr, Nelson EB, Brusman-Lovins LA, et al. Psychiatric and legal features of 113 men convicted of sexual offenses. Journal of Clinical Psychiatry. 2004;65(3):293-300.

48. Kraanen FL, Emmelkamp PMG. Substance misuse and substance use disorders in sex offenders: A review. Clinical Psychology Review. 2011;31(3):478-489.

49. Poortinga E, Lemmen C, Majeske K. A comparison of criminal sexual conduct defendants based on victim age. Journal of Forensic Sciences. 2007;52(6):1372-1375.

50. Rojas EY, Gretton HM. Background, offence characteristics, and criminal outcomes of aboriginal youth who sexually offend: A closer look at aboriginal youth intervention needs. Sexual Abuse: Journal of Research and Treatment. 2007;19(3):257-283. 
51. Abracen J, Looman J, Anderson D. Alcohol and drug abuse in sexual and nonsexual violent offenders. Sexual Abuse: A Journal of Research and Treatment. 2000;12(4):263-274.

52. Abracen J, Looman J, Di Fazio R, et al. Patterns of attachment and alcohol abuse in sexual and violent non-sexual offenders. Journal of Sexual Aggression. 2006;12(1):19-30.

53. Kubik EK, Hecker JE, Righthand S. Adolescent females who have sexually offended: Comparisons with delinquent adolescent female offenders and adolescent males who sexually offend. Journal of Child Sexual Abuse. 2003;11(3):63-83.

54. Looman J, Abracen J, DiFazio R. Alcohol and Drug Abuse among Sexual and Nonsexual Offenders: Relationship to Intimacy Deficits and Coping Strategy. Sexual Abuse: A Journal of Research and Treatment. 2004;16(3):177-189.

55. Johnson SA. Intoxicated Perpetrators of Sexual Assault \& rape know what they are doing despite Intoxication: What the Literature Has to Say. Journal of Forensic Sciences \& Criminal Investigation. 2017;1(4):555-570.

56. Aromäki AS, \& Lindman RE. Alcohol expectancies in convicted rapists and child molesters. Criminal Behavior and Mental Health. 2001;11(2):94-101.

57. Greenberg DM, Firestone P, Nunes KL, et al. Biological fathers and stepfathers who molest their daughters: Psychological, phallometric, and criminal features. Sexual Abuse: A Journal of Research and Treatment. 2005;17(1):39-46.

58. Eher R, Neuwirth W, Fruehwald S, et al. Sexualization and lifestyle impulsivity: Clinically valid discriminators in sexual offenders. International Journal of Offender Therapy and Comparative Criminology. 2003;47(4):452-467.

59. Giotakos O, Markianos M, Vaidakis N. Aggression, impulsivity, and plasma sex hormone levels in a group of rapists, in relation to their history of childhood attention-deficit/ hyperactivity disorder symptoms. The Journal of Forensic Psychiatry \& Psychology. 2005;16(2):423-433.

60. Hanson RK, Harris AJR. Dynamic predictors of sexual recidivism (No. 1998-01). Department of the Solicitor General of Canada, Ottawa. 1998.

61. Hanson RK, Harris A. A structured approach to evaluating change among sex offenders. Sexual Abuse: A Journal of Research and Treatment. 2001;13(2):105-122.

62. Jeglic EL, Mercado CC, Levenson JS. The Prevalence and Correlates of Depression and Hopelessness among Sex Offenders Subject to Community Notification and Residence Restriction Legislation. American Journal of Criminal Justice. 2012;37(1):46-59.

63. Seto M.C. Pedophilia and sexual offending against children: Theory, assessment, and intervention. Washington, DC, US: American Psychological Association. 2008.

64. McKibben A, Proulx J, Lusignan R. Relationships between conflict, affect and deviant sexual behaviors in rapists and pedophiles. Behavior Research Therapy. 1994;32(5):571-575.

65. Stinson JD, Becker JV, Tromp S. A preliminary study on findings of psychopathy and affective disorders in adult sex offenders. International Journal of Law and Psychiatry. 2005;28:637-649.

66. Harsch S, Bergk JE, Steinert T, et al. Prevalence of mental disorders among sexual offenders in forensic psychiatry and prison. International Journal of Law and Psychiatry. 2006;29(5):443-449.

67. Nunes KL, McPhail IV, Babchishin KM. Social anxiety and sexual offending against children: A cumulative meta-analysis. Journal of Sexual Aggression. 2012;18(3):284-293.

68. Ward T, Polaschek D, Beech AR. Theories of sexual offending. England: John Wiley \& Sons LTD. 2006.

69. Gudjonsson GH, Sigurdsson JF. Differences and similarities between violent offenders and sex offenders. Child Abuse \& Neglect. 2000;24(3):363-372.

70. Kafka M. Axis I psychiatric disorders, paraphilic sexual offending and implications for pharmacological treatment. Isr J Psychiatry and Relat Sci. 2012;49(4):255-261.

71. Hoyer J, Kunst H, Schmidt A. Social Phobia as a Comorbid Condition in Sex Offenders with Paraphilia or Impulse Control Disorder. Journal of Nervous \& Mental Disease. 2001;189(7):463-70.

72. Mann RE, Marshall WL. Advances in the Treatment of Adult Incarcerated Sex Offenders. In: Beech AR, Craig LA, Browne KD, editors. Assessment and treatment of sex offenders: A handbook. West Sussex: John Wiley \& Sons. 2009;329-347 p.

73. Hunter JA, Figueredo AE. The Influence of Personality and History of Sexual Victimization in the Prediction of Juvenile Perpetrated Child Molestation. Behavior Modification. 2000;24(2):241-263.

74. Davis GE, Leitenberg H. Adolescent sex offenders. Psychological Bulletin. 1987;101(3):417-427.

75. Salter D, McMillan D, Richards M, et al. Development of sexually abusive behavior in sexually victimized males: A longitudinal study. Lancet. 2003;361(9356):471-476.

76. Widom CS, Ames MA. Criminal consequences of childhood sexual victimization. Child Abuse \& Neglect. 1994;18(4):303-318.

77. Ford ME, Linney JA. Comparative analysis of juvenile sexual offenders, violent nonsexual offenders, and status offenders. Journal of Interpersonal Violence. 1995;10(1):56-70.

78. Hall DK, Mathews F, Pearce J. Sexual behavior problems in sexually abused children: A preliminary typology. Child Abuse \& Neglect. 2002;26(3):289-312.

79. McCuish EC, Cale J, Corrado RR. Abuse Experiences of Family Members, Child Maltreatment, and the Development of Sex Offending Among Incarcerated Adolescent Males: Differences between Adolescent Sex Offenders and Adolescent Non-Sex Offenders. Inter $J$ of Offender Therapy and Comparative Criminology. 2017;61(2):127-149.

80. Pithers WD, Gray A, Busconi A, et al. Children with sexual behavior problems: Identification of five distinct child types and related treatment considerations. Child Maltreatment. 1998;3(4):384-406.

81. Spaccarelli S, Bowden B, Coatsworth JD, et al. Psychosocial correlates of male sexual aggression in a chronic delinquent sample. Criminal Justice and Behavior. 1997;24(1):71-95.

82. Johnson GM, Knight RA. Developmental antecedents of sexual coercion in juvenile sexual offenders. Sexual Abuse: A Journal of Research and Treatment. 2000;12(3):165-179.

83. Knight RA, Sims-Knight JE. The developmental antecedents of sexual coercion against women: Testing alternative hypotheses with structural equation modeling. Annals of the New York Academy of Science. 2003;989:72-85.

84. Marshall WL, Barbaree HE. An integrated theory of the etiology of sexual offending. In: Marshall WL, Laws DR, Barbaree HE, editors. Handbook of Sexual Assault: Issues, theories and treatment of the offender. New York: Plenum Press. 1990;257-275.

85. Deblinger E, Steer R, Lippmann J. Maternal factors associated with sexually abused children's psychosocial adjustment. Child Maltreatment. 1999;4(1):13-20.

86. Friedrich WN. Psychological assessment of sexually abused children and their families. London, England: SAGE. 2002.

87. Kuo JR, Goldin PR, Werner K, et al. Childhood trauma and current psychological functioning in adults with social anxiety disorder. Journal of Anxiety Disorders. 2011;25(4):467-473. 
88. Marshall WL, Marshall LE. The origins of sexual offending. Trauma Violence, and Abuse. 2000;1(3):250-263.

89. Seto MC, Barbaree HE. Sexual aggression as antisocial behavior: A developmental model. In: Stoff DM, Breiling J, Maser JD, editors. Handbook of antisocial behavior. 1997;524-533 p.

90. Smallbone SW. Social and psychological factors in the development of delinquency and sexual deviance. In: Barbaree HE, Marshall WL, editors. The juvenile sex offender. New York, NY: Guilford Press. 2006;105-127 p.

91. Marziano V, Ward T, Beech AR, et al. Identification of five fundamental implicit theories underlying cognitive distortions in child abusers: A preliminary study. Psychology, Crime \& Law. 2006;12(1):97-105.

92. Alden LE, Taylor CT. Interpersonal processes in social phobia. Clinical Psychology Review. 2004;24(7):857-882.

93. Stein MB, Stein DJ. Social anxiety disorder. The Lancet 2008;371(9618):1115-1125.

94. Widom CS, Maxfield MG. An Update on the "Cycle of Violence." Research in Brief. U.S. Department of Justice, Office of Justice Programs, National Institute of Justice. 2001.

95. Fedoroff JP, Pinkus S. The genesis of pedophilia: Testing the "Abuse-to-abuser" hypothesis. Journal of Offender Rehabilitation. 1996;23(3-4):85-101.

96. Freund K, Wilson RJ, Dickey R. Does sexual abuse in childhood cause pedophilia: An exploratory study. Archives of Sexual Behavior. 1990;19(6):557-568.

97. Simons DA, Wurtele SK, Durham RL. Developmental experiences of child sexual abusers and rapists. Child Abuse \& Neglect. 2008;32(5):549-560.

98. Knight RA, Sims-Knight JE. Testing an etiological model for male juvenile sexual offending against females. Journal of Child Sexual Abuse. 2005;13(3-4):33-55.

99. Salter AC. Treating child sex offenders and victims: A practical guide. Sage Publications. 1988.

100. Christie MM, Marshall WL, Lanthier RD. A descriptive study of incarcerated rapists and pedophiles. Ottawa, Canada: Report to the Solicitor General of Canada. 1979

101. Groth AN, Burgess AW, Holmstrom LL. Rape: Power, anger and sexuality American Journal of Psychiatry. 1977;134(11):1239-1243.

102. Chantry K, Craig RJ. Psychological screening of sexually violent offenders with the MCMI. Journal of Clinical Psychology. 1994;50(3):430-435.

103. Chen YY, Chen CY, Hung DL. Assessment of psychiatric disorders among sex offenders: Prevalence and associations with criminal history. Criminal Behaviour and Mental Health. 2016;26(1):30-37.

104. Foley TP. Forensic assessment of Internet child pornography offenders. In: Schwartz BK, editor. The Sex Offender. Kingston, NJ: Civic Research Institute. 2002;4:1-17.

105. Seto MC, Eke AW. The criminal histories and later offending of child pornography offenders. Sexual Abuse: A Journal of Research and Treatment. 2005;17(2):201-210.

106. Eysenck HJ. Sex and personality. London: Open Books. 1976.

107. Kosson DS, Kelly JC, White JW. Psychopathy-related traits predict selfreported sexual aggression among college men. Journal of Interpersonal Violence. 1997;12(2):241-254.

108. Rapaport K, Burkhart BR. Personality and attitudinal characteristics of sexually coercive college males. Journal of Abnormal Psychology. 1984;93(2): 216-221.
109. Hare RD. Psychopathy: A clinical construct whose time has come. Criminal Justice and Behavior. 1996;23(1):25-54.

110. Hare RD. The psychopathy checklist revised, 2nd ed. Toronto, Canada: Multi-Health Systems. 2003.

111. Lang S, Kliteberg B, Alm PO. Adult psychopathy and violent behavior in males with early neglect and abuse. Acta Psychiactiaca Scadanavia, 2002;106(412):93-100.

112. Arrigo BA, Griffin A. Serial murder and the case of Aileen Wuornos Attachment theory, psychopathy, and predatory aggression. Behavioral Sciences \& the Law. 2004;22(3):375-393.

113. Bowlby J. Attachment. Attachment and loss: Volume 1. New York: Basic Books. 1969.

114. Lynam DR. Early identification of the fledgling psychopath: Locating the psychopathic child in the current nomenclature. Journal of Abnormal Psychology. 1998;107(4):566-575.

115. Frick PJ, O'Brien BS, Wootten JM, et al. Psychopathy and conduct problems in children. Journal of Abnormal Psychology, 1994;102(4):700-707.

116. Hecht D. An inter-hemispheric imbalance in the psychopath's brain. Personality and Individual Differences. 2011;51:3-10.

117. Blair RJ. The amygdala and ventromedial prefrontal cortex: Functional contributions and dysfunction in psychopathy. Philosophical Transactions of the Royal Society of London. Series B. Biological Sciences. 2008;363(1503):2557-2565.

118. Blair KS, Newman C, Mitchess DGV, et al. Differentiating among prefrontal substrates in psychopathy: Neuropsychological test findings. Neuropsychology. 2006;20(2):153-165.

119. Roussy S, Toupin J. Behavioral inhibition deficits in juvenile psychopaths Aggressive Behavior. 2000;26(6):413-424.

120. Lykken DT. The antisocial personalities. Hillside, NJ: Lawrence Erlbaum Associates. 1995.

121. O Connor. Antisocial, personality, sociopathy, and psychopathy. Mega Links in criminal justice. 2006.

122. Quinsey VL, Chaplin TG, Varney G. A comparison of rapists' and nonsex offenders' sexual preference for mutually consenting sex, rape, and physical abuse of women. Behavioral Assessment. 1981;3:127-135.

123. Bourke ML, Hernandez AE. The "Butner Study" redux: A report of the incidence of hands-on child victimization by child pornography offenders. Journal of Family Violence. 2009;24:183-191.

124. Langstrom N, Seto M. Exhibitionistic and voyeuristic behavior in a Swedish national population survey. Archives of Sexual Behavior. 2006;35(4):427-435

125. Galbreath N, Berlin F, Sawyer D. Paraphilias and the internet. In: Cooper A, editor. Sex and the Internet: A Guidebook for Clinicians. Philadelphia: Brunner- Routledge. 2002;187-205 p.

126. Babchishin KM, Hanson RK, Hermann CA. The characteristics of online sex offenders: A meta-analysis. Sexual Abuse: A Journal of Research and Treatment. 2011;23:92-123.

127. JABM, Sijtsema JJ, Bogaerts S. From child pornography to child sexual abuse: A review of child pornography offender characteristics and risks for cross-over. Aggression and Violent Behavior. 2014;19(5):466-473.

128. van Dam C. Identifying Child Molesters: Preventing Child Sexual Abuse by Recognizing the Patterns of Offenders. Binghamton, NY: The Haworth Press. 2001

129. Craven S, Brown S, Gilchrist E. Sexual grooming of children: Review of literature and theoretical considerations. Journal of Sexual Aggression. 2006;12(3):287-299. 
130. Jones LM, Finkelhor D, Kopiec K. Why is sexual abuse declining? A survey of state child protection administrators. Child Abuse \& Neglect. 2001;25(9):1139-1158.

131. Wolak J, Finkelhor D, Mitchell K. Child pornography possessors arrested in Internet-related crimes. Alexandria, VA: National Center for Missing \& Exploited Children. 2005.

132. Grubin D. Sex offending against children: Understanding the risk. Police research series paper 99. London. Home Office. National Criminal Justice Reference Service. 1998

133. Heil P, English K. Sex offender polygraph testing in the United States: Trends and controversies. In: Wilcox DT, editor. The use of polygraph in assessing, treating and supervising sex offenders: A practitioners' guide. United Kingdom: Wiley-Blackwell. 2009;181-216 p.

134. Long ML, Alison LA, McManus MA. Child pornography and likelihood of contact abuse: A comparison between contact child sexual offenders and non-contact offenders. Sexual Abuse: A Journal of Research and Treatment. 2013;25(4):370-395.

135. Owens JN, Eakin JD, Hoffer T, et al. Investigative aspects of crossover offending from a sample of FBI online child sexual exploitation cases. Aggression and Violent Behavior. 2016;30:3-14.

136. NSOPW. Raising awareness about sexual abuse: Facts and statistics. US Department of Justice. 2019.

137. Snyder HN. Sexual assault of young children as reported to law enforcement: Victim, incident and offender characteristics, in A NIBRS Statistical Report. U.S. Department of Justice: Washington, D.C. 2000.

138. Hoffler T, Muirhead Y, Owens J, et al. Like a puppet on a string Understanding grooming behaviors of child sex offenders. Crimes Against Children: Behavioral and investigative perspectives. FBI's behavioral analysis unit. 2015.

139. Krone T. A typology of online child pornography offending. Trends \& Issues in Crime and Criminal Justice. 2004;279.

140. Elliott IA, Beech AR, Mandeville-Norden R, et al. Psychological profiles of internet sexual offenders: Comparisons with contact sexual offenders. Sexual Abuse: A Journal of Research and Treatment. 2009;21(1):76-92.

141. Ward T, Siegert RJ. Toward a comprehensive theory of child sexual abuse: A theory knitting perspective. Psychology, Crime and Law. 2002;8(4):319-351.

142. Armstrong J, Mellor D. Internet child pornography offenders: An examination of attachment and intimacy deficits. Legal and Criminological Psychology. 2016;21(1):41-55.

143. Babchishin KM, Hanson RK, VanZuylen H. Online child pornography offenders are different: A meta-analysis of the characteristics of online and offline sex offenders against children. Archives of Sexual Behavior. 2015;44(1):45-66.

144. Faust E, Bickart W, Renaud C, et al. Child pornography possessors and child contact sex offenders: A multilevel comparison of demographic characteristics and rates of recidivism. Sexual Abuse: A Journal of Research and Treatment. 2015;27(5):460-478.

145. Henshaw M, Ogloff JRP, Clough JA. Demographic, mental health, and offending characteristics of online child exploitation material offenders: A comparison with contact-only and dual sexual offenders. Behavioral Sciences \& the Law. 2018;36(2):198-215.

146. Jung S, Ennis L, Stein S, et al. Child pornography possessors: Comparisons and contrasts with contact- non-contact sex offenders. Journal of Sexual Aggression. 2012;19(3):295-310.

147. Seto MC, Wood MJ, Babchishin KM, Flynn S. Online solicitation offenders are different from child pornography and lower risk contact sexual offenders. Law and Human Behavior. 2012;36(4):320-330.
48. Aslan D, Edelmann R. Demographic and offence characteristics: A comparison of sex offenders convicted of possessing indecent images of children, committing contact sex offences or both offences. Journal of Forensic Psychiatry and Psychology. 2014;25(2):121-134.

149. Bates A, Metcalf C. A psychometric comparison of Internet and nonInternet sex offenders from a community treatment sample. Journal of Sexual Aggression. 2007;13(1):11-20.

150. Clevenger SL, Navarro JN, Jasinski JL. A matter of low self-control? Exploring differences between child pornography possessors and child pornography producers/distributors using self-control theory. Sexual Abuse: A Journal of Research and Treatment. 2016;28(6):555-571.

151. Howitt D, Sheldon K. The role of cognitive distortions in paedophilic offending: Internet and contact offenders compared. Psychology, Crime \& Law. 2007;13(5):469-486.

152. Magaletta PR, Faust E, Bickart W, et al. Exploring clinical and personality characteristics of adult male internet-only child pornography offenders. International Journal of Offender Therapy and Comparative Criminology. 2014;58(2):137-153

153. Middleton D, Mandeville-Norden R, Hayes E. Does treatment work with internet sex offenders? Emerging findings from the internet sex offender treatment programme (i- SOTP). Journal of Sexual Aggression. 2009;15(1):5-19.

154. Navarro JN, Jasinski JL. Demographic and motivation differences among online sex offenders by type of offense: An exploration of routine activities theories. Journal of Child Sexual Abuse. 2015;24(7):753-771.

155. Shelton J, Eakin J, Hoffer T, et al. Online child sexual exploitation: An investigative analysis of offender characteristics and offending behavior. Aggression and Violent Behavior. 2016;30:15-23.

156. Webb L, Craissati J, Keen S. Characteristics of Internet child pornography offenders: A comparison with child molesters. Sexual Abuse. 2007;19(4):449-465

157. Ray JV, Kimonis ER, Seto MC. Correlates and moderators of child pornography consumption in a community sample. Sexual Abuse: A Journal of Research and Treatment. 2014;26(6):523-545.

158. Burke A, Sowerbutts S, Blundell B, et al. Child pornography and the internet: Policing and treatment issues. Psychiatry, Psychology and Law. 2002;9(1):79-84

159. Elliott IA, Ashfield S. The use of online technology in the modus operand of female sex offenders. Journal of Sexual Aggression. 2011;17(1):92-104.

160. Seigfried KC, Lovely RW, Rogers MK. Self-reported online child pornography behavior: A psychological analysis. International Journal of Cyber Criminology. 2008;2(1):286-297.

161. Seigfried-Spellar KC, Rogers MK. Low neuroticism and high hedonistic traits for female internet child-pornography consumers. Cyberpsychology, Behavior and Social Networking. 2010;13(6):729-635.

162. Tomak S, Weschler FS, Ghahramanlou-Holloway M, et al. An empirical study of the personality characteristics of internet sex offenders. Journal of Sexual Aggression. 2009;15(2):139-148.

163. Mitchell KJ, Finkelhor D, Wolak J. The internet and family and acquaintance sexual abuse. Child Maltreatment. 2005;10(1):49-60.

164. Endrass J, Urbaniok F, Hammermeister LC, et al. The consumption of internet child pornography and violent and sex offending. BMC Psychiatry. 2009;9:43

165. Seto MC, Eke AW. Predicting recidivism among adult male child pornography offenders: Development of the child pornography offender risk tool (CPORT). Law and Human Behavior. 2015;39(4):416-429.

166. Williams R, Elliott IA, Beech AR. Identifying sexual grooming themes used by Internet sex offenders. Deviant Behavior. 2013;34(2):135-152. 
167. Henry O, Mandeville-Norden R, Hayes E, et al. Do internet-based sexual offenders reduce to normal, inadequate and deviant groups? Journal of Sexual Aggression. 2010;16(1):33-46.

168. Neutze J, Seto M, Schaefer GA, et al. Predictors of child pornography offenses and child sexual abuse in a community of pedophiles and hebephiles. Sexual Abuse: A Journal of Research and Treatment. 2011;23(2):212-242.

169. McManus MA, Long ML, Alison L, et al. Factors associated with contact child sexual abuse in a sample of indecent image offenders. Journal of Sexual Aggression. 2015;21(3):368-384.

170. Quayle E, Taylor M. Model of problematic internet use in people with a sexual interest in children. Cyber Psychology \& Behavior. 2003;6(1):93106.

171. Elliott IA, Beech AR, Mandeville-Norden R. The psychological profiles of internet, contact, and mixed internet/contact sex offenders. Sexual Abuse: A Journal of Research and Treatment. 2013;25(1):3-20.

172. Langan PA, Smith EL, Durose MR. Recidivism of sex offenders released from prison in 1994. Washington, DC: US Department of Justice. Bureau of Justice Statistics. 2003.

173. Seto MC, Hanson KR, Babchishin KM. Contact sexual offending by men with online sexual offenses. Sexual Abuse: A Journal of Research and Treatment. 2011;23(1):124-145.

174. Merdian HL, Moghaddam N, Boer DP, et al. Fantasy-driven versus contact-driven users of child sexual exploitation material: Offender classification and implications for their risk assessment. Sexual Abuse. 2018;30(3):230-253.

175. Eke AW, Seto MC, Williams J. Examining the criminal history and future offending of child pornography offenders: An extended prospective followup study. Law and Human Behavior. 2011;35(6):466-478.

176. Price M, Lambie I, Krynen AM. New Zealand adult internet child pornography offenders. Journal of Criminal Psychology. 2015;5(4):262278 .

177. Seto MC, Cantor JM, Blanchard R. Child pornography offenses are a valid diagnostic indicator of pedophilia. Journal of Abnormal Psychology. 2006;115(3):610-615.

178. Middleton D, Elliott IA, Mandeville-Norden R, et al. An investigation into the applicability of the Ward and Siegert Pathways Model of child sexual abuse with internet offenders. Psychology, Crime and Law. 2006;12(6):589-603.

179. Quayle E, Taylor M. Child pornography and the internet: Perpetuating a cycle of abuse. Deviant Behavior: An Interdisciplinary Journal. 2002;23(4):331-361.

180. Wood MJ, Seto MC, Flynn S, et al. Is it "just” pictures? The use of polygraph with internet offenders who deny abusive sexual contact. 28th Annual Conference of the Association for the Treatment of Sexual Abusers, Dallas, TX, USA. 2009.

181. Briken P, Hill A, Berner W. Substance abuse and sexual offending. In: Saleh FM, Grudzinskas AJ, Bradford JM, editors. Sex offenders: Identification, risk assessment, treatment, and legal issues. New York, NY: Oxford University. 2009;265-275 p.

182. Peugh J, Belenko S. Examining the substance use patterns and treatment needs of incarcerated sex offenders. Sexual Abuse: A Journal of Research and Treatment. 2001;13(3):179-195.

183. Beier KM, Grundmann D, Kuhle LF, et al. The German Dunkelfeld Project: A pilot study to prevent child sexual abuse and the use of child abusive images. The Journal of Sexual Medicin. 2015;12(2):529-542.

184. Cantor JM, Klein C, Lykins A, et al. A treatment-oriented typology of self-identified hypersexuality referrals. Archives of Sexual Behavior. 2013;42(5):883-893.
85. Cooper A, Delmonico DL, Burg R. Cybersex users, abusers, and compulsives: New findings and implications. Sexual Addiction \& Compulsivity. 2000;7(1-2):5-29.

186. Cooper A, McLaughlin IP, Campbell KM. Sexuality in cyberspace: Update for the 21st century. Sexual Addiction \& Compulsivity. 2000;3(4):521.

187. Merdian HL, Curtis C, Thakker J, et al. The endorsement of cognitive distortions: Comparing child pornography offenders and contact sex offenders. Psychology, Crime and Law. 2014;20(10):971-993.

188. Howitt D. Pornography and the paedophile: Is it criminogenic? British Journal of Medical Psychology. 1995;68:15-27.

189. Quayle E, Vaughan M, Taylor M. Sex offenders, internet child abuse images and emotional avoidance: The importance of values. Aggression and Violent Behavior. 2006;11(1):1-11.

190. Lanning KV. Child molesters: A behavioral analysis, 4th ed. Alexandria, VA: National Center for Missing \& Exploited Children. 2001

191. Taylor M, Holland G, Quayle E. Typology of paedophile picture collections. Police Journal. 2001;74(2):97-107.

192. Calcetas-Santos O. Child pornography on the Internet. In: Arnaldo $\mathrm{CA}$, editor. Child Abuse on the Internet: Ending the Silence. New York: Berghahn. 2001;5764 p.

193. DeHart D, Dwyer G, Seto MC, et al. Internet sexual solicitation of children: A proposed typology of offenders based on their chats, e- mails, and social network posts. Journal of Sexual Aggression. 2017;23(1):77-89.

194. Grosskopf A. Online interactions involving suspected paedophiles who engage male children. Trends and Issues in Crime and Criminal Justice. 2010;403:1-6.

195. Kloess JA, Seymour-Smith S, Hamilton-Giachritsis CE, et al. A qualitative analysis of offenders' modus operandi in sexually exploitative interactions with children online. Sexual Abuse: A Journal of Research and Treatment. 2017;1(29):1-29.

196. Webster S, Davidson J, Bifulco A, et al. Final report. European Online Grooming Project. 2012.

197. Broom LJ, Izura C, Lorenzo-Dus N. A systematic review of fantasy driven vs. contact driven internet initiated sexual offences: Discrete or overlapping typologies? Child Abuse \& Neglect. 2018;79:434- 444.

198. Finkelhor D. The prevention of childhood sexual abuse. The Future of Children. 2009;19(2):169-194.

199. Wolak J, Finkelhor D, Mitchell KJ, et al. Online "predators" and their victims: Myths, realities, and implications for prevention and treatment. Psychology of Violence. 2010;1(S):13-35.

200. Wolak J, Finkelhor D, Mitchell KJ. Internet-initiated sex crimes agains minors: Implications for prevention based on findings from a national study. Journal of Adolescent Health. 2004;35(5):11-20.

201. Young K. Profiling online sex offenders, cyber-predators, and pedophiles. Journal of Behavioral Profiling. 2005;5(1):1-18.

202. Wolak J, Finkelhor D, Mitchell KJ, et al. Online "predators" and their victims: Myths, realities, and implications for prevention and treatment. American Psychologist. 2008;63(2):111-128.

203. Malesky LA Jr. Predatory online behavior: Modus operandi of convicted sex offenders in identifying potential victims and contacting minors over the internet. Journal of Child Sexual Abuse. 2007;16(2):22-32.

204. Wolak J, Finkelhor D. Are crimes by online predators different from crimes by sex offenders who know youth in-person? Journal of Adolescent Health. 2013;53(6):736-741.

205. O Connell R. A typology of cyber sexploitation and online grooming practices. Cyberspace Research Unit. University of Central Lancashire. 2003. 
206. Marcum C. Interpreting the intentions of internet predators: An examination of online predatory behavior. Journal of Child Sexual Abuse. 2007;16(4):99-114.

207. Mitchell KJ, Wolak J, Finkelhor D. Police posing as juveniles online to catch sex offenders: Is it working? Sexual Abuse: A Journal of Research and Treatment. 2005;17(3):241-267.

208. Black PJ, Wollis M, Woodworth M, et al. A linguistic analysis of grooming strategies of online child sex offenders: Implications for our understanding of predatory sexual behavior in an increasingly computer-mediated world Child Abuse \& Neglect. 2015;44:140-149.

209. McAlinden AM. 'Setting 'Em Up': Personal, familial and institutional grooming in the sexual abuse of children. Social \& Legal Studies. 2006;15(3):339-362.

210. Hanson RK. Recidivism and age: Follow-up data from 4,673 sexual offenders. Journal of Interpersonal Violence. 2002;17(10):1046-1062.

211. Marshall WL, Serran GA, Marshall LE. Situational and dispositiona factors in child sexual molestation: A clinical perspective. In: Wortley $\mathrm{R}$ Smallbone S, editors. Situational Prevention of Child Sexual Abuse. Crime Prevention Studies, volume 19. 2006;37-63.

212. Smallbone S, Marshall WL, Wortley R. Preventing Child Sexual Abuse Evidence, Policy and Practice. UK: Willan Publishing. 2008.

213. Sheldon K, Howitt D. Sexual fantasy in paedophile offenders: Can any model explain satisfactorily new findings from a study of internet and contact sexual offenders? Legal and Criminological Psychology. 2008;13(1):137-158.

214. Sheldon K, Howitt D. Sex offenders and the Internet. John Wiley \& Sons Ltd: West Sussex, England. 2007.

215. Langevin R, Curone $\mathrm{S}$. The use of pornography during the commission of sexual offenses. International Journal of Offender Therapy and Comparative Criminology. 2004;28(5):572-586.

216. Buschman J, Wilcox D, Krapohl D, et al. Cyber sex offender risk assessment An explorative study. Journal of Sexual Aggression. 2010;16(2):197-209.

217. Laulik S, Allam J, Sheridan L. An investigation into maladaptive personality functioning in internet sex offenders. Psychology, Crime and Law. 2007;13(5):523-535.

218. Lee JKP, Jackson HJ, Pattison P, et al. Developmental risk factors for sexual offending. Child Abuse \& Neglect. 2002;26(1):73-92.

219. Simons D, Wurtele SK, Heil P. Childhood victimization and lack of empathy as predictors of sexual offending against women and children. Journal of Interpersonal Violence. 2002;17(12):1291-1305.

220. Craissati J, McClurg G, Browne K. The parental bonding experiences of sex offenders: A comparison between child molesters and rapists. Child Abuse \& Neglect. 2002;26(9):909-921.

221. Olson LN, Daggs JL, Ellevold BL, et al. "Entrapping the Innocent: Toward a Theory of Child Sexual Predators' Luring Communication." Communication Theory. 2007;17(3):231-251.

222. Dandescu A, Wolfe R. Considerations on fantasy use by child molesters and exhibitionists. Sexual Abuse: A Journal of Research and Treatment. 2003;15(4):297-305.

223. Riegel D. Effect on boy-attracted pedosexual males of viewing boy erotica (Letter to the Editor). Archives of Sexual Behavior. 2004;33(4):321-323.

224. Wilson D, Jones T. 'In my own World': A case study of a paedophiles' thinking and doing and his use of the internet. The Howard Journal of Criminal Justice. 2008;47(2):107-120.

225. Kettleborough DG, Meridan HL. Gateway to offending behavior: Permission- giving thoughts of online users of child sexual exploitation material. Journal of Sexual Aggression. 2017;23(1):19-32.

226. Marshall WL, Barbaree HE, Eccles A. Early onset and deviant sexuality in child molesters. Journal of Interpersonal Violence. 1991;6(3):323-336.
227. Warren J, Hazelwood R, Dietz P. The sexually sadistic serial killer. Journal of Forensic Sciences. 1996;41(6):970-974.

228. Kennedy-Souza B. Internet addiciton disorder. Interpersonal Computing and Technology. 1998;6:1-2.

229. Lanning K. Investigators guide to allegations of "ritual child abuse". Quantico: V Behavioral Science Unit. National Centre for the Analysis of Violent Crime. FBI Academy. 1992.

230. Seto MC, Maric A, Barbaree HE. The role of pornography in the etiology of sexual aggression. Aggression and Violent Behavior. 2001;6(1):35-53.

231. Lorenzo-Dus N, Izura C, Pérez-Tattam R. Understanding grooming discourse in computer-mediated environments. Discourse, Context and Media. 2016;12:40-50.

232. Lorenzo-Dus N, Izura C. "cause ur special": Understanding trust and complimenting behaviour in online grooming discourse. Journal of Pragmatics, 2017;112:68-82.

233. De Santistebana P, Del Hoyo J, Alcázar-Córcoles MA, et al. Progression, maintenance, and feedback of online child sexual grooming: A qualitative analysis of online predators. Child Abuse \& Neglect. 2018;80:203-215.

234. Bergen E, Antfolk J, Jern P, et al. Adults' sexual interest in children and adolescents online: A quasi-experimental study. International Journal of Cyber Criminology. 2013;7(2):94-111.

235. Staksrud E. Online grooming legislation: Knee-jerk regulation? European Journal of Communication. 2013;28(2):152-167.

236. Barber CS, Bettez SC. Deconstructing the online grooming of youth Toward improved information systems for detection of online sexua predators. Thirty fifth international conference on information systems. 2014.

237. Bergen E. Comparing adult-youth and adult-adult online sexual solicitation: Manipulative behaviors, situational factors, and outcomes. Doctoral Thesis. Abo: Abo Akademy University. 2014.

238. Villacampa C, Gómez M. Online child sexual grooming. International Review of Victimology. 2017;23(2):105-121.

239. Whittle H, Hamilton-Giachritsis C, Beech A. A comparison of victim and offender perspectives of grooming and sexual abuse. Deviant Behavior. 2015;36(7):1-26.

240. Kloess J, Hamilton-Giachritsis C, Beech A. Offense processes of online sexual grooming and abuse of children via internet communication platforms. Sexual Abuse: A Journal of Research and Treatment. 2019;31(3):73-96.

241. Van Gijn-Grosvenor E, Lamb M. Behavioural differences between online sexual groomers approaching boys and girls. Journal of Child Sexual Abuse. 2016;25(5):577-596.

242. Santisteban de P, Gámez-Guadix M. Persuasion strategies in online child grooming: A qualitative analysis with aggressors in prison. Psychosocial Intervention. 2017;26(3):139-146.

243. Mitchell KJ, Finkelhor D, Wolak J. Youth internet users at risk for the most serious online sexual solicitations. American Journal of Preventive Medicine. 2007b;32(6):532-537.

244. Mitchell KJ, Finkelhor D, Wolak J. Risk factors for and impact of online sexual solicitation of youth. Jama. 2001;285(23):3011-3014.

245. Mitchell KJ, Finkelhor D, Wolak J. Online requests for sexual pictures from youth: Risk factors and incident characteristics. Journal of Adolescent Health. 2007a;41(2):196-203.

246. Proulx J, Perreault C, Ouimet M. Pathways in the offending process of extrafamilial sexual child molesters. Sexual Abuse: A Journal of Research and Treatment. 1999;11(2):117-129.

247. Ward T, Hudson SM. Sexual offenders' implicit planning: A conceptua model. Sexual Abuse: A Journal of Research and Treatment. 2000;12(3):189-202. 
248. Ward T, Louden K, Hudson SM, et al. A descriptive model of the offense chain for child molesters. Journal of Interpersonal Violence. 1995;10(4):452-472.

249. Langevin R, Lang R, Curnoe S. The prevalence of sex offenders with deviant fantasies. Journal of Interpersonal Violence. 1998;13(3):315-327.

250. Berson IR. Grooming cybervictims: The psychosocial effects of online exploitation for youth. Journal of School Violence. 2003;2(1):5-18.

251. Singer MI, Hussey D, Strom KJ. Grooming the victim: An analysis of a perpetrator's seduction letter. Child Abuse \& Neglect. 1992;16(6):872-886.

252. Elliott M, Browne K, Kilcoyne J. "Child Sexual Abuse Prevention: What Offenders Tell Us.” Child Abuse and Neglect. 1995;19(5):579-594.

253. Mooney JL, Ost S. "Group Localised Grooming: What Is It and What Challenges Does It Pose for Society and Law?" Child and Family Law Quarterly 2013;25(4):1-20.

254. Berliner L, Conte JR. "The Process of Victimization: The Victims' Perspective."Child Abuse \& Neglect. 1990;14(1):29-40.

255. Christiansen JR, Blake RH. "The Grooming Process in Father-Daughter Incest.” In: Anne Horton L, Barry L Johnson, Lynn M Roundy, editors. The Incest Perpetrator: A Family Member No One Wants to Treat. 1990;88-98 p.

256. Lang RA, Frenzel RR. "How Sex Offenders Lure Children." Annals of Sex Research. 1988;1(2):303-317.

257. Leclerc B, Proulx J, Beauregard E. "Examining the Modus Operandi of Sexual Offenders against Children and Its Practical Implications." Aggression and Violent Behavior. 2009;14(1):5-12.

258. Whittle HC, Hamilton-Giachritsis CE, Beech AR. "Under his spell": Victims' perspectives of being groomed online. Social Sciences. 2014;3:404-426.

259. Dowdell EB, Burgess AW, Flores JR. Online social networking patterns among adolescents, young adults, and sexual offenders. American Journal of Nursing. 2011;111(7):28-36.

260. Quayle E, Allegro S, Hutton L, et al. Rapid skill acquisition and online sexual grooming of children. Computers in Human Behavior. 2014;39:368-375.

261. Campbell AM. False faces and broken lives: An exploratory study of the interaction behaviors used by male sex offenders in relating to victims. Journal of Language and Social Psychology. 2009;28(4):428-440.

262. Krone T. Queensland police stings in online chat rooms. Trends \& Issues in Crime and Criminal Justice. 2005;301:1-6.

263. Quayle E, Allegro S, Hutton L, et al. Online behavior related to child sexual abuse: Creating a private space in which to offend. Interviews with online child sex offenders. 2012.

264. Sullivan J, Quayle E. Manipulation styles of abusers who work with children. In: Erooga M, editor. Creating safer organisations: Practical steps to prevent the abuse of children by those working with them. Chichester, UK: John Wiley. 2012;85-98 p.

265. Bazarova NN. Public intimacy: Disclosure interpretation and social judgments on Facebook. Journal of Communication. 2012;62(5):815-832.

266. Chiu MM, Seigfried-Spellar KC, Ringenberg TR. Exploring detection of contact vs. fantasy online sexual offenders in chats with minors: Statistical discourse analysis of self- disclosure and emotion words. Child Abuse \& Neglect. 2018;81:128-138.

267. Dale A, Davies A, Wei L. Developing a typology of rapists' speech. Journal of Pragmatics. 1997;27(5):653-669.
268. Durkin KF. Misuse of the Internet by pedophiles: Implications for law enforcement and probation practice. Federal Probation. 1997;61:14-18.

269. Dindia K. Self-disclosure research: Knowledge through meta-analysis. In Allen M, Preiss RW, Gayle BM, Burrell NA, editors. LEA's communication series. Interpersonal communication research: Advances through metaanalysis. 2002;169-185 p.

270. Ward T, Keenan T. Child molesters' implicit theories. Journal of Interpersonal Violence. 1999;14(8):821-838.

271. Winder B, Gough B. "I never touched anybody-that's my defence": A qualitative analysis of internet sex offender accounts. Journal of Sexual Aggression. 2010;16(2):125-141.

272. Elliot IA. Psychological characteristics of users of child pornography on the internet. (Doctoral dissertation). 2012.

273. Gannon TA, Hoare JA, Rose MR, et al. A re-examination of female child molesters' implicit theories: evidence of female specificity? Psychology, Crime \& Law. 2009;18(2):209-2444.

274. Polaschek DLL, Calvert SW, Gannon TA. Linking violent thinking: Implicit theory-based research with violent offenders. Journal of Interpersonal Violence. 2009;24(1):75-96.

275. Ó Ciardha $\mathrm{C}$, Ward T. Theories of cognitive distortions in sexual offending: What the current research tells us. Trauma, Violence, \& Abuse. 2013;14(1):5-21.

276. Beech A, Fisher D, Ward T. Sexual murderers' implicit theories. Journal of Interpersonal Violence. 2005;20(11):1366-1389.

277. Ó Ciardha C, Gannon TA. The implicit theories of firesetters: A preliminary conceptualization. Aggression and Violent Behavior. 2012;17(2):122-128.

278. Glasgow D. The potential of digital evidence to contribute to risk assessment of internet offenders. Journal of Sexual Aggression. 2010;16(1):87-106.

279. Sullivan J. The spiral of sexual abuse: A conceptual framework for understanding and illustrating the evolution of sexually abusive behaviour. NOTA News. 2002;41:17-21.

80. Sullivan J, Beech AR. Assessing internet sex offenders. In: Calder M, editor. Child sexual abuse and the internet: Tackling the new frontier. Dorset: Russell House. 2004;69-83 p.

281. Osborn J, Elliott IA, Middleton D, et al. The use of actuarial risk assessment measures with UK internet child pornography offenders. Journal of Aggression, Conflict and Peace Research. 2010;2(3):16-24.

282. Carr J, Hilton Z. Child Protection and self-regulation in the internet industry: The UK experience. Children and Society. 2009;23(4):303-308.

283. Abel GG, Becker JV, Cunningham-Rathner J. Complications, consent, and cognitions in sex between children and adults. International Journal of Law and Psychiatry. 1984;7(1):89-103.

84. Bumby KM. Assessing the cognitive distortions of child molesters and rapists: Development and validation of the MOLEST and RAPE scales. Sexual Abuse: A Journal of Research and Treatment. 1996;8(1):37-54.

285. Burns DD. The feeling good handbook. New York, NY: William Morrow and Co. 1989.

286. Neidigh L, Krop H. Cognitive distortions among child sexual offenders. Journal of Sex Education \& Therapy. 1992;18(3):208-215.

287. Ó Ciardha C, Gannon TA. The cognitive distortions of child molesters are in need of treatment. Journal of Sexual Aggression. 2011;17(2):130-141.

288. Pollack NL, Hashmall JM. The excuses of child molesters. Behavioral Sciences \& the Law. 1991;9(1):53-59. 
289. Lussier P, Cale J. Beyond sexual recidivism: A review of the sexual 304 criminal career parameters of adult sex offenders. Aggression and Violent Behavior, 2013;18(5):445-457.

290. Smith DW, Letourneau EJ, Saunders BE, et al. Delay of disclosure in childhood rape: Results from a national survey. Child Abuse and Neglect. 2000;24(2):273-287.

291. Bourke ML, Fragomeli L, Detar PJ, et al. The use of tactical polygraph with sex offenders, Journal of Sexual Aggression. 2015;21(3):354-367.

292. Gannon TA, Wood JL, Pina A, et al. An evaluation of mandatory polygraph testing for sexual offenders in the United Kingdom. Sexual Abuse. 2013;26(2):178-203.

293. McAlinden AM. Grooming and the sexual abuse of children: Implications for sex offender assessment, treatment and management. Sexual Offender Treatment. 2013;8(1).

294. Drouin M, Boyd RL, Hancock JT, et al. Linguistic analysis of chat transcripts from child predator undercover sex stings. The Journal of Forensic Psychiatry and Psychology. 2017;28(4):437-457.

295. Abel GG, Gore DK, Holland CL, et al. The measurement of the cognitive distortions of child molesters. Annals of Sex Research. 1989;2(2):135-152.

296. Abel GG, Mittleman MS, Becker JV. Sex offenders: Results of assessment and recommendations for treatment. In: Ben-Aron $\mathrm{MH}$, Hucker SJ, Webster CD, editors. Clincial criminology: The assessment and treatment of criminal behavior. Toronton, Canada: M \& M Graphics. 1985;207-220 p.

297. Alexy EM, Burgess AN, Baker T. Internet offenders: Traders, travelers, and combination trader-travelers. Journal of Interpersonal Violence. 2005;20(7):804-812.

298. Diagnostic and statistical manual of mental disorders, 5th ed. American Psychiatric Association. 2013.

299. Bartels RM, Merdian HL. The implicit theories of child sexual exploitation material users: An initial conceptualization. Aggression and Violent Behavior. 2016;26:16-25.

300. Finkelhor D, Ormrod R, Turner H, et al. The victimization of children and youth: A comprehensive, national study. Child Maltreatment. 2005;10(1):5-25.

301. Finkelhor D, Ormrod R, Chaffin M. Juveniles who commit sex offenses against minors. Juvenile Justice Bulletin. U.S. Department of Justice. 2009

302. Hanson C. What can be done to stop predators? MSNBC News/Dateline Interview of Dr Fred Berlin. 2006.

303. Lanning KV. Child Molestation: A law enforcement typology. In Hazelwood RR, Burgess AW, editors. Practical Aspects of Rape Investigation: A Multidisciplinary Approach, 2nd ed. Boca Raton, Florida: CRC Press, Inc. 1995.
04. Lanning KV, Burgess AW. Child molesters who abduct. National Center for Missing \& Exploited Children. Violence Vict. 1991;6(3):213-224.

305. Marshall WL, Laws DR, Barbaree HE. Handbook of sexual assault. New York: Plenum Press. 1990;55-60.

306. Marshall WL, Marshall LE, Serran G, et al. Self-esteem, shame, cognitive distortion and empathy in sexual offenders: Their integration and treatment implications. Psychology Crime and Law Crime \& Law. 2009;15(2):217-234.

307. Perez PR. The etiology of psychopathy: A neuropsychological perspective. Aggression and Violent Behavior. 2012;17(6):519-522.

308. Schmitt DP, Shackelford TK, Buss DM. Are men really more 'oriented' toward short-term mating than women? A critical review of theory and research, Psychology, Evolution \& Gender. 2001;3(3):211-239.

309. Seto MC, Reeves L, Jung S. Explanations given by child pornography offenders for their crimes. Journal of Sexual Aggression. 2010;16(2):169-180.

310. Taylor M, Quayle E. Child pornography: An internet crime. Hove, UK: Brunner Routledge. 2003.

311. Ward T. Sexual offenders' cognitive distortions as implicit theories Aggression and Violent Behavior. 2000;5(5):491-507.

312. Ward T, Louden K, Hudson S. A Descriptive mode of the offense chain for child molesters. Journal of Interpersonal Violence. 1995;10(4):452-472.

313. Widom CS, White HR. Problem behaviours in abused and neglected children grown up: prevalence and co-occurrence of substance abuse, crime and violence. Criminal Behaviour and Mental Health. 2006;7(4):287-310.

314. Winder B, Gough B, Seymour-Smith S. Stumbling into sexual crime: The passive perpetrator in accounts by male internet sex offenders. Archives of Sexual Behavior. 2015;44(1):167-180.

315. Winters G, Kaylor L, Jeglic E. "I Knew It All Along: The Sexual Grooming Behaviors of Child Molesters and the Hindsight Bias." Journal of Child Sexual Abuse. 2016;25(1):20-36.

316. Winters G, Kaylor L, Jeglic E. Sexual offenders contacting children online: An examination of transcripts of sexual grooming. The Journal of Sexual Aggression. 2017;23(1):62-76.

317. Wortley R, Smallbone S. Applying situational principles to sexual offenses against children. In: Wortley R, Smallbone S, editors. Situational Prevention of Child Sexual Abuse. Crime Prevention Studies. Cullompton, Devon, UK: Willan Publishing. 2006;19:7-35 p. 